\title{
Influence of Ligand Denticity and Flexibility on the Molecular Copper Mediated Oxygen Reduction Reaction
}

Nicole W. G. Smits, Bas van Dijk, Iris de Bruin, Samantha L. T. Groeneveld, Maxime A. Siegler, and Dennis G. H. Hetterscheid*

Cite This: Inorg. Chem. 2020, 59, 16398-16409

Read Online

ACCESS

Llll Metrics \& More

Article Recommendations

Supporting Information

ABSTRACT: To date, the copper complex with the tris(2pyridylmethyl)amine (tmpa) ligand (Cu-tmpa) catalyzes the ORR with the highest reported turnover frequency (TOF) for any molecular copper catalyst. To gain insight into the importance of the tetradentate nature and high flexibility of the tmpa ligand for efficient four-electron ORR catalysis, the redox and electrocatalytic ORR behavior of the copper complexes of $2,2^{\prime}: 6^{\prime}, 2^{\prime \prime}$-terpyridine (terpy) and bis(2-pyridylmethyl)amine (bmpa) (Cu-terpy and Cu-bmpa, respectively) were investigated in the present study. With a combination of cyclic voltammetry and rotating ring disk electrode measurements, we demonstrate that the presence of the terpy and bmpa ligands results in a decrease in catalytic ORR activity and an increase in Faradaic efficiency for $\mathrm{H}_{2} \mathrm{O}_{2}$ production.

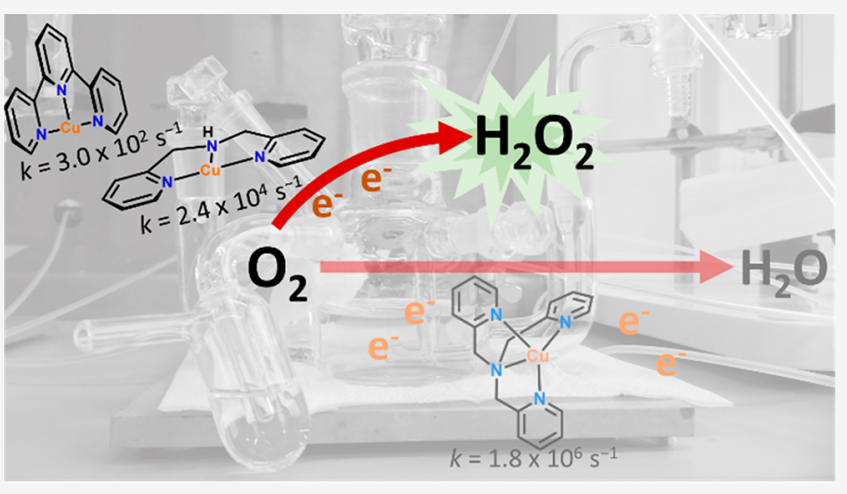
The lower catalytic activity is shown to be the result of a stabilization of the $\mathrm{Cu}^{\mathrm{I}}$ state of the complex compared to the earlier reported Cu-tmpa catalyst. This stabilization is most likely caused by the lower electron donating character of the tridentate terpy and bmpa ligands compared to the tetradentate tmpa ligand. The Laviron plots of the redox behavior of $\mathbf{C u}$-terpy and $\mathbf{C u}$-bmpa indicated that the formation of the ORR active catalyst involves relatively slow electron transfer kinetics which is caused by the inability of $\mathbf{C u}$-terpy and $\mathbf{C u}$-bmpa to form the preferred tetrahedral coordination geometry for a $\mathrm{Cu}^{\mathrm{I}}$ complex easily. Our study illustrates that both the tetradentate nature of the tmpa ligand and the ability of Cu-tmpa to form the preferred tetrahedral coordination geometry for a $\mathrm{Cu}^{\mathrm{I}}$ complex are of utmost importance for ORR catalysis with very high catalytic rates.

\section{INTRODUCTION}

The transition from fossil fuels to sustainable energy sources is an important step to achieve a renewable future. For this purpose, both the storage and the conversion of fuels such as hydrogen play a key role. To minimize energy loss during the fuel-to-energy conversion, efficient fuel cells are required. A significant obstacle which limits applicability of fuel cells on a large scale is the energy loss related to the overpotential required for the cathodic oxygen reduction reaction (ORR)., ${ }^{1,2}$

In nature, multicopper oxidases couple the oxidation of substrate near a mononuclear copper site to efficient ORR catalysis at a trinuclear copper site. ${ }^{3}$ For multicopper oxidase laccase, ORR catalysis takes place with TOFs from 2 to 560 $\mathrm{s}^{-1},{ }^{4-8}$ and when immobilized on electrodes, laccases have been reported to be able to operate significantly closer to the equilibrium potential of water than the platinum-based heterogeneous catalysts that are typically employed in fuel cell chemistry. ${ }^{9-16}$ In order to shed light on how the ORR can be mediated in a more efficient manner in an artificial system, a wide range of copper systems has been reported in the last three decades as biomimetic models for active sites in multicopper oxidases due to their dioxygen activation reactivity. $^{17-36}$

With almost 2 million turnovers per second $\left(1.8 \cdot 10^{6} \mathrm{~s}^{-1}\right)$, the highest catalytic rates reported thus far for oxygen reduction mediated by a homogeneous copper catalyst have been reported for a copper complex with the tris(2pyridylmethyl)amine (tmpa) ligand (Cu-tmpa). ${ }^{37}$ The dioxygen binding chemistry and catalytic ORR behavior of Cu-tmpa have been studied extensively. ${ }^{36-44}$ Reduction of dioxygen occurs via a stepwise mechanism wherein hydrogen peroxide is obtained as an isolable and obligatory intermediate. ${ }^{37}$ The binding constant $k_{\mathrm{O}_{2}}=1.3 \cdot 10^{9} \mathrm{M}^{-1} \mathrm{~s}^{-1}$ of dioxygen binding to $\left[\mathrm{Cu}^{\mathrm{I}}(\mathbf{t m p a})\right]^{+}$determined in THF is roughly in the same ballpark as the TOF under aqueous conditions where the oxygen concentration equals $1.1 \mathrm{mM}^{39}$

Received: July 24, 2020

Published: October 27, 2020 
It therefore seems likely that binding of dioxygen to $\left[\mathrm{Cu}^{\mathrm{I}}(\mathrm{tmpa})\right]^{+}$is rate limiting. Formation of dinuclear species via coupling of $\left[\mathrm{Cu}^{\mathrm{I}}(\mathbf{t m p a})\right]^{+}$with $\left[\mathrm{Cu}^{\mathrm{II}}(\mathbf{t m p a})\right]$-superoxide as detected in organic solvent is most likely too slow to play a role under catalytic conditions. ${ }^{38,40}$ Due to the very high activity of Cu-tmpa, rates are typically mass-transport limited in either dioxygen or phosphate buffer. At diluted concentrations, however, a first order dependence in copper was observed. ${ }^{37}$ Noteworthy is that the onset potential and activity of the ORR with respect to the reduction of hydrogen peroxide lie in favor of the first reaction resulting in a buildup of hydrogen peroxide under conditions where the reaction is not run under masstransport limitations of dioxygen. The overpotential of an optimized catalyst therefore is probably limited by the equilibrium potential of hydrogen peroxide at $0.68 \mathrm{~V}$ versus RHE. Questions that remain are to which extent the activity, selectivity, and overpotential of the ORR can be adjusted individually and whether a direct four-electron reduction of dioxygen near the equilibrium potential of water is feasible.

Marcus theory dictates that the rates of redox reactions are affected by their accompanying reorganization energies. ${ }^{45}$ This largely relates to the ability of ligands to accommodate the metal site at multiple oxidation states and to switch between these geometries via facile transitions. To investigate how the overall TOF for the ORR mediated by single copper sites is affected by intrinsic reorganization barriers, and which effect this has on the catalyst selectivity and the entire catalyst profile, we investigated the ORR mediated by copper complexes employed with the rigid terpy and the more dynamic bmpa ligands (terpy $=2,2^{\prime}: 6^{\prime}, 2^{\prime \prime}$-terpyridine $), \quad$ bmpa $=(\operatorname{bis}(2$ pyridylmethyl)amine)).

\section{RESULTS AND DISCUSSION}

Synthesis. As previously reported, complexation of terpy and bmpa with one equivalent of $\mathrm{a} \mathrm{Cu}^{\mathrm{II}}$ salt is expected to result in the complexes $\left[\mathrm{Cu}(\right.$ terpy $\left.) \mathrm{LX}_{2}\right]$ and $\left[\mathrm{Cu}(\right.$ bmpa $\left.) \mathrm{LX}_{2}\right]$, respectively. ${ }^{46-50}$ The triflate complexes $\left[\mathrm{Cu}(\right.$ terpy $)\left(\mathrm{H}_{2} \mathrm{O}\right)$ $\left.(\mathrm{OTf})_{2}\right]$ and $\left[\mathrm{Cu}(\mathbf{b m p a})\left(\mathrm{H}_{2} \mathrm{O}\right)(\mathrm{OTf})_{2}\right]$ will be referred to as Cu-terpy and Cu-bmpa, respectively (Figure 1). The

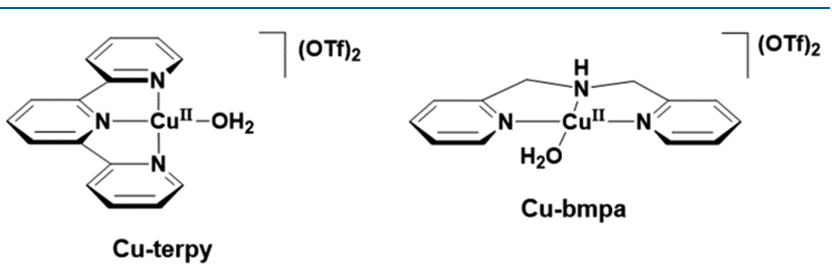

Figure 1. Structure of mononuclear copper complexes investigated during the present study.

structures depicted in Figure 1 are a simplification of a situation in which either the triflate counterions or additional water molecules are expected to coordinate weakly at the axial positions. The synthesis of the mononuclear copper complexes Cu-terpy and Cu-bmpa is described in Section 1.2 of the Supporting Information. Both complexes were characterized by elemental analysis and UV-vis spectroscopy (see Section 1.2 in the Supporting Information). The latter indicated that both complexes are stable in an aqueous $\mathrm{pH} 7$ buffered solution for at least a few days (Figure S1). EPR spectroscopy and X-ray diffraction studies are in line with an elongated octahedral, square pyramidal, or square planar geometry for Cu-bmpa and an elongated octahedral geometry for Cu-terpy, respectively (see Sections 3 and 4 in the Supporting Information).

Redox Behavior of Cu-terpy and Cu-bmpa. Using a glassy carbon working electrode (GC WE), the redox behavior of mononuclear copper complexes Cu-terpy and Cu-bmpa was investigated by performing cyclic voltammetry $(\mathrm{CV})$ measurements in an aqueous $\mathrm{pH} 7$ buffered electrolyte. Under $1 \mathrm{~atm}$ Ar, Cu-terpy shows one $\mathrm{Cu}^{\mathrm{II}} / \mathrm{Cu}^{\mathrm{I}}$ redox couple in $0.1 \mathrm{M} \mathrm{pH} 7$ phosphate buffer (Figure 2a). At a scan rate of $100 \mathrm{mV} \mathrm{s}^{-1}$, this redox couple is located at a half-wave potential $\left(E_{1 / 2}\right)$ of $0.31 \mathrm{~V}$ vs RHE. The peak-to-peak potential separation $\left(\Delta E_{\mathrm{p}}\right)$ amounts to $76 \mathrm{mV}$. This relatively large $\Delta E_{\mathrm{p}}$ value indicates that the $\mathrm{Cu}^{\mathrm{II}} / \mathrm{Cu}^{\mathrm{I}}$ redox couple of $\mathrm{Cu}$-terpy is not a perfect reversible one-electron redox process at a scan rate of $100 \mathrm{mV} \mathrm{s}^{-1} .{ }^{51}$ The slight irreversibility is confirmed by an observed difference of $\sim 5 \mu \mathrm{C}$ in buildup charge during the anodic and cathodic events, for which 13 and $8 \mu \mathrm{C}$ were recorded, respectively.

For Cu-bmpa, at least two overlapping $\mathrm{Cu}^{\mathrm{II}} / \mathrm{Cu}^{\mathrm{I}}$ redox couples were observed in $\mathrm{pH} 7$ phosphate buffer under 1 atm Ar (Figure S4a). However, only one $\mathrm{Cu}^{\mathrm{II}} / \mathrm{Cu}^{\mathrm{I}}$ redox couple was observed for Cu-bmpa in 0.1 M pH 7 HEPES buffer in 0.1 $\mathrm{M} \mathrm{NaClO}_{4}$ (Figure 2b). It can therefore be concluded that the observed additional redox couple of $\mathbf{C u}$-bmpa in the presence of phosphate buffer is most likely the result of the formation of a phosphate coordinated Cu-bmpa complex. At a scan rate of $100 \mathrm{mV} \mathrm{s}^{-1}$, the $\mathrm{Cu}^{\mathrm{II}} / \mathrm{Cu}^{\mathrm{I}}$ redox couple of $\mathbf{C u}$-bmpa is located at $E_{1 / 2}=0.30 \mathrm{~V}$ vs RHE in HEPES buffered $\mathrm{NaClO}_{4}$ electrolyte with $\Delta E_{\mathrm{p}}$ amounting to $56 \mathrm{mV}$. This peak-to-peak separation is in agreement with a homogeneous system undergoing a reversible one-electron redox process. ${ }^{51}$ The more reversible character of the redox couple of Cu-bmpa compared to the redox couple of Cu-terpy is confirmed by a smaller difference in buildup charge during the anodic and cathodic events of the redox couple of Cu-bmpa which amounts to only $\sim 2 \mu \mathrm{C}$ in favor of the former.

Scan Rate Dependence Study of Redox Behavior. The redox behavior of Cu-terpy and Cu-bmpa was further assessed by performing a scan rate dependence study under $1 \mathrm{~atm} \mathrm{Ar}$ (Figure 2). During this study, it was found that the $\Delta E_{\mathrm{p}}$ value of the $\mathrm{Cu}^{\mathrm{II}} / \mathrm{Cu}^{\mathrm{I}}$ redox couple of Cu-terpy increases significantly with the scan rate. At the lowest applied scan rate $\left(10 \mathrm{mV} \mathrm{s}^{-1}\right)$, the $\Delta E_{\mathrm{p}}$ value for the $\mathrm{Cu}^{\mathrm{II}} / \mathrm{Cu}^{\mathrm{I}}$ redox couple of Cu-terpy amounts to $55 \mathrm{mV}$. For $\mathbf{C u}$-bmpa, the $\Delta E_{\mathrm{p}}$ value of the $\mathrm{Cu}^{\mathrm{II}} / \mathrm{Cu}^{\mathrm{I}}$ redox couple was found to increase slightly for scan rates above $100 \mathrm{mV} \mathrm{s}^{-1}$. At the highest scan rate applied during this study $\left(500 \mathrm{mV} \mathrm{s}^{-1}\right)$, this $\Delta E_{\mathrm{p}}$ value amounts to 71 $\mathrm{mV}$. The increase in the $\Delta E_{\mathrm{p}}$ value above a scan rate of 100 $\mathrm{mV} \mathrm{s}^{-1}$ indicates that the electron transfer of the $\mathrm{Cu}^{\mathrm{II}} / \mathrm{Cu}^{\mathrm{I}}$ redox couple of $\mathbf{C u}$-bmpa becomes relatively slow above this scan rate. ${ }^{51}$

For both Cu-terpy and Cu-bmpa, the observed increase in $\Delta E_{\mathrm{p}}$ value with higher applied scan rate is the result of a significant positive shift in peak potential of the anodic event of the $\mathrm{Cu}^{\mathrm{II}} / \mathrm{Cu}^{\mathrm{I}}$ redox couple and a minor negative shift in peak potential of the cathodic event of the $\mathrm{Cu}^{\mathrm{II}} / \mathrm{Cu}^{\mathrm{I}}$ redox couple. This effect is depicted in the Laviron plots of Figure 3 in which the peak potentials of the anodic and cathodic events have been plotted vs the logarithm of the scan rate.

As shown in Figure 3, the positive shift in peak potential of the anodic event with increasing scan rate is larger than the negative shift in peak potential of the cathodic event for both complexes. It can therefore be concluded that electron transfer is especially limited by charge transfer kinetics for the oxidation 

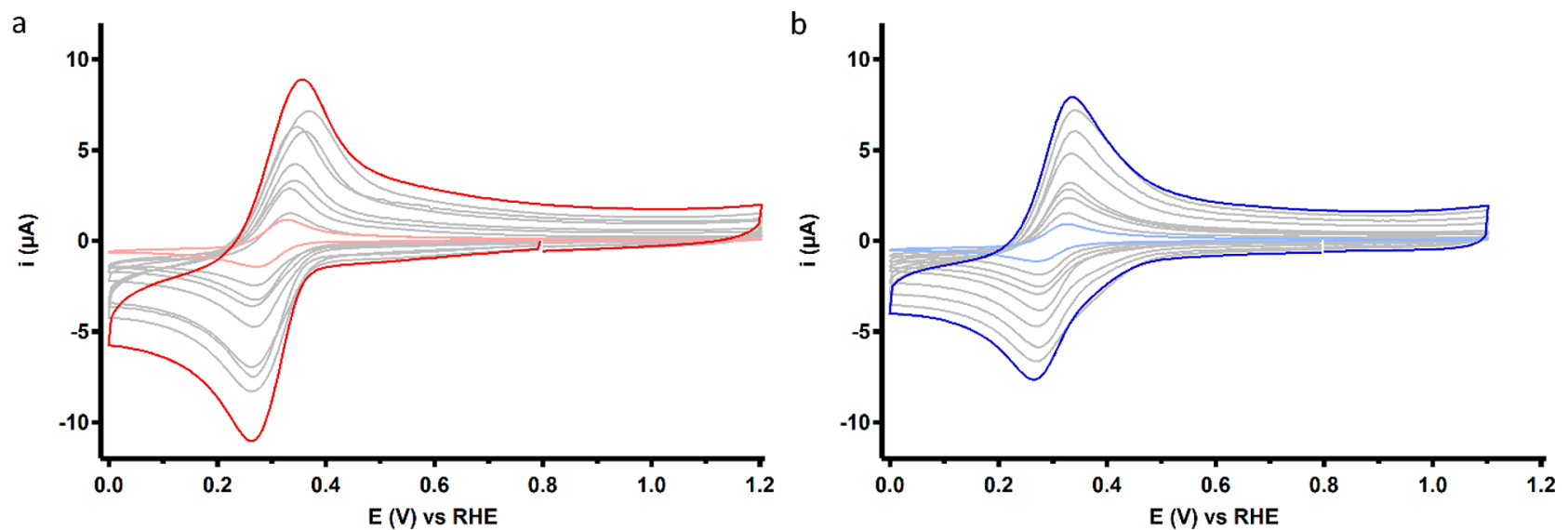

Figure 2. Cyclic voltammograms of $0.3 \mathrm{mM}$ Cu-terpy in $0.1 \mathrm{M} \mathrm{pH} 7$ phosphate buffer (a) and $0.3 \mathrm{mM} \mathrm{Cu}$-bmpa in $0.1 \mathrm{M} \mathrm{pH} 7 \mathrm{HEPES}$ buffered $0.1 \mathrm{M} \mathrm{NaClO}_{4}$ (b) at a range of scan rates between 10 and $500 \mathrm{mV} \mathrm{s}^{-1}$ (light to dark colored lines with intermediate gray lines). For both complexes, only the first scan of each measurement is depicted. Conditions: 1 atm Ar, $293 \mathrm{~K}$, GC WE.
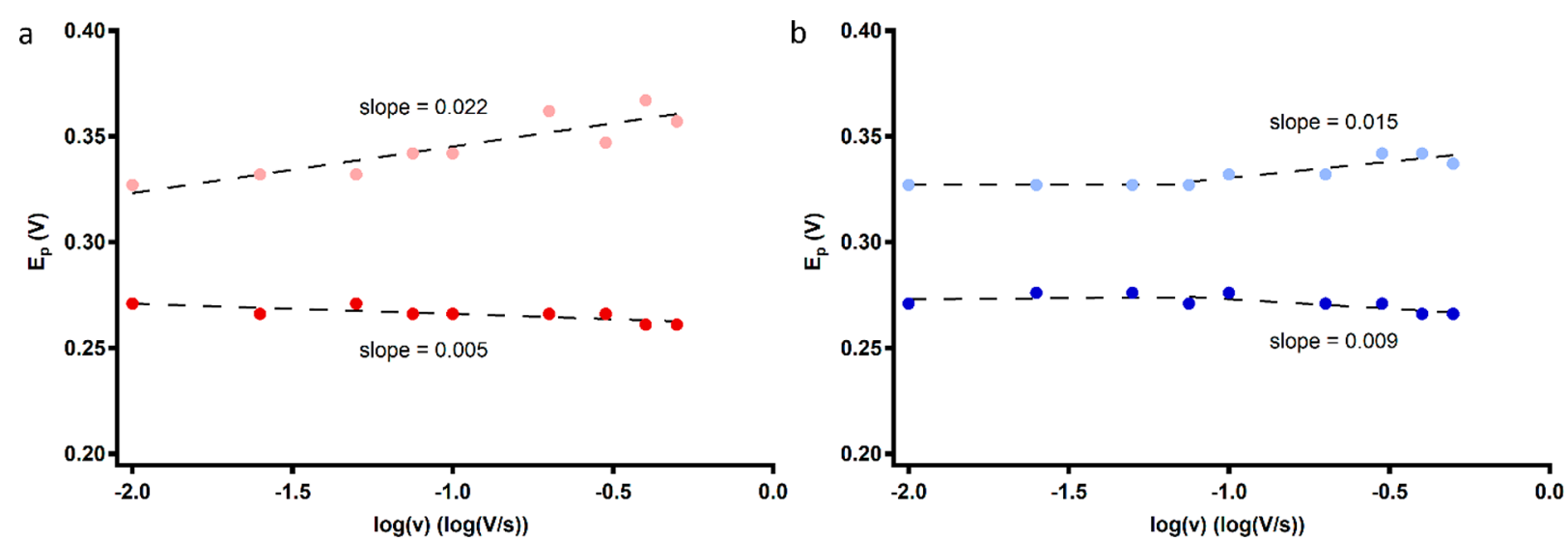

Figure 3. Laviron plots of the anodic (light colored dots) and the cathodic (dark colored dots) events of $0.3 \mathrm{mM} \mathrm{Cu}$-terpy in $0.1 \mathrm{M}$ pH 7 phosphate buffer (a) and $0.3 \mathrm{mM} \mathrm{Cu}$-bmpa in $0.1 \mathrm{M} \mathrm{pH} 7$ HEPES buffered $0.1 \mathrm{M} \mathrm{NaClO}_{4}$ (b) at a range of scan rates between 10 and $500 \mathrm{mV} \mathrm{s}$. Slope coefficients of the fit between 10 and $500 \mathrm{mV} \mathrm{s}^{-1}$ for Cu-terpy and between 100 and $500 \mathrm{mV} \mathrm{s}^{-1}$ for Cu-bmpa are depicted as well. Conditions: $1 \mathrm{~atm}$ Ar, $293 \mathrm{~K}$, GC WE.
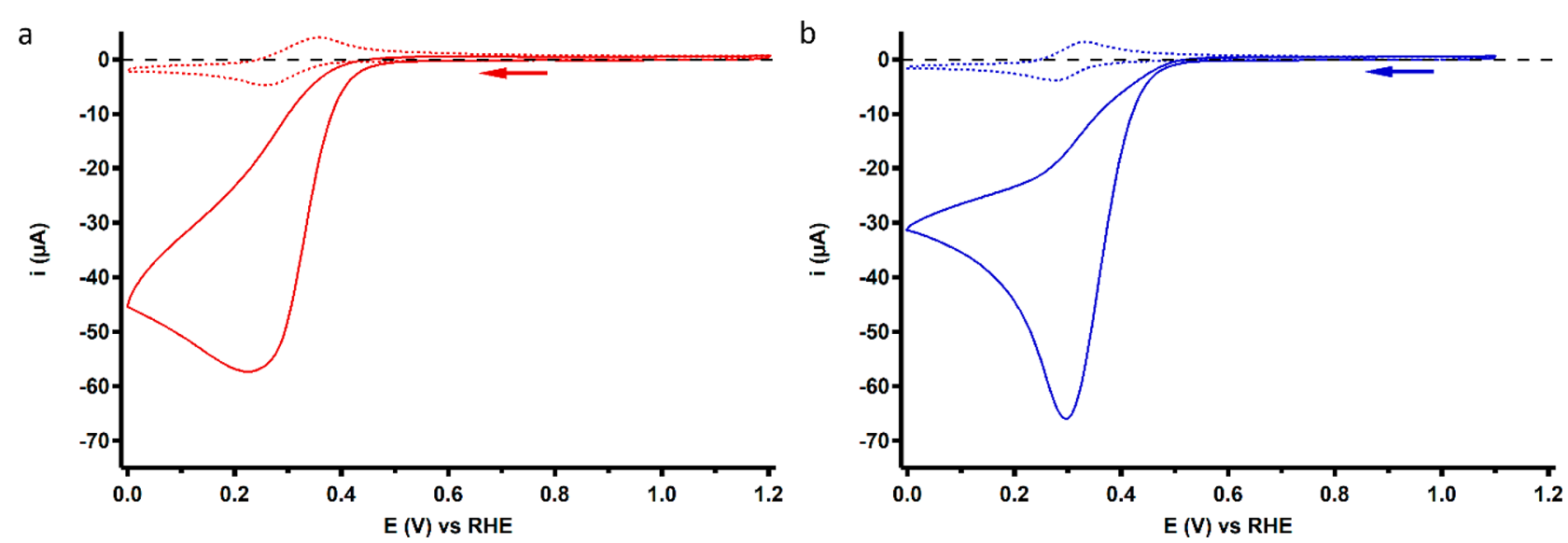

Figure 4. Cyclic voltammograms of $0.3 \mathrm{mM}$ Cu-terpy in $0.1 \mathrm{M} \mathrm{pH} 7$ phosphate buffer (a) and $0.3 \mathrm{mM}$ Cu-bmpa in $0.1 \mathrm{M}$ pH $7 \mathrm{HEPES}$ buffered $0.1 \mathrm{M} \mathrm{NaClO}_{4}$ (b) under $1 \mathrm{~atm} \mathrm{O}_{2}$ (solid lines) and $1 \mathrm{~atm}$ Ar (dotted lines). For both complexes, only the first scan of each measurement is depicted. Conditions: $293 \mathrm{~K}, \mathrm{GC}$ WE, $100 \mathrm{mV} \mathrm{s}^{-1}$ scan rate.

of the $\mathrm{Cu}^{\mathrm{I}}$ state of Cu-terpy and Cu-bmpa back to the initial $\mathrm{Cu}^{\mathrm{II}}$ state. This basically means that the low electron transfer rate is only able to keep up with the scan rate when the latter is kept low. The difference between the scan rate at which the $\mathrm{Cu}^{\mathrm{II}} / \mathrm{Cu}^{\mathrm{I}}$ redox couple of Cu-terpy and Cu-bmpa is still reversible $\left(10 \mathrm{mV} \mathrm{s}^{-1}\right.$ for Cu-terpy and $100 \mathrm{mV} \mathrm{s}^{-1}$ for $\mathbf{C u}$ bmpa) indicates that the electron transfer kinetics of the anodic event is faster for Cu-bmpa than it is for Cu-terpy. For both complexes, a linear dependence between the peak current and the square root of the scan rate $\left(\nu^{1 / 2}\right)$ is obtained, which is 


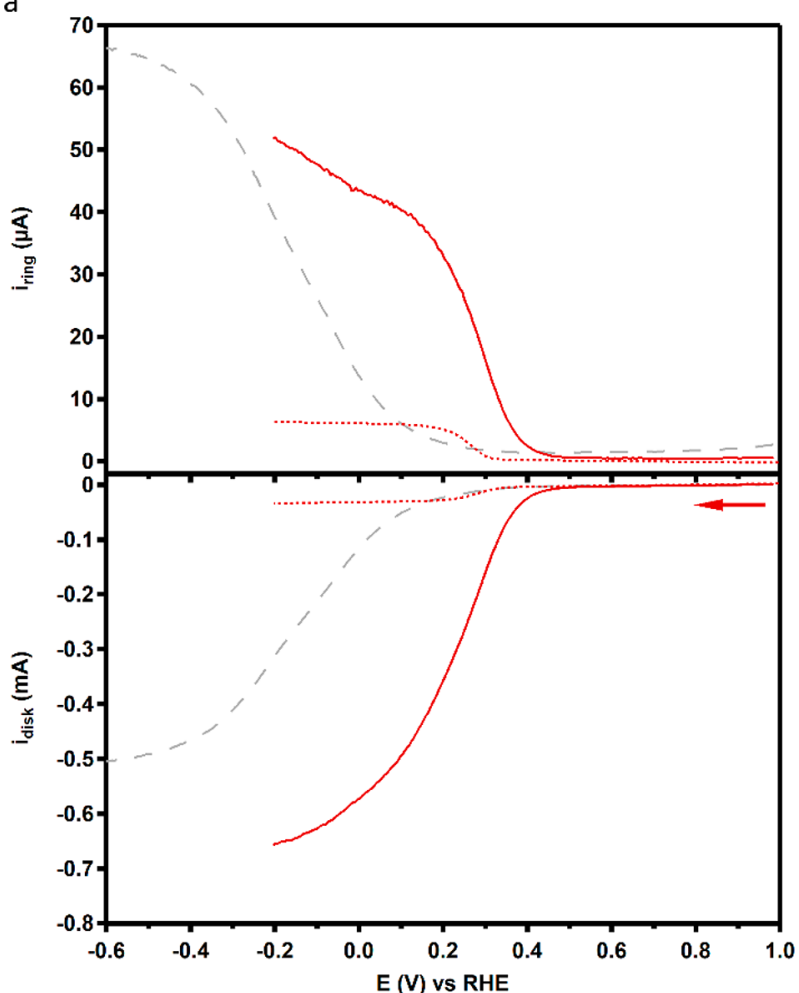

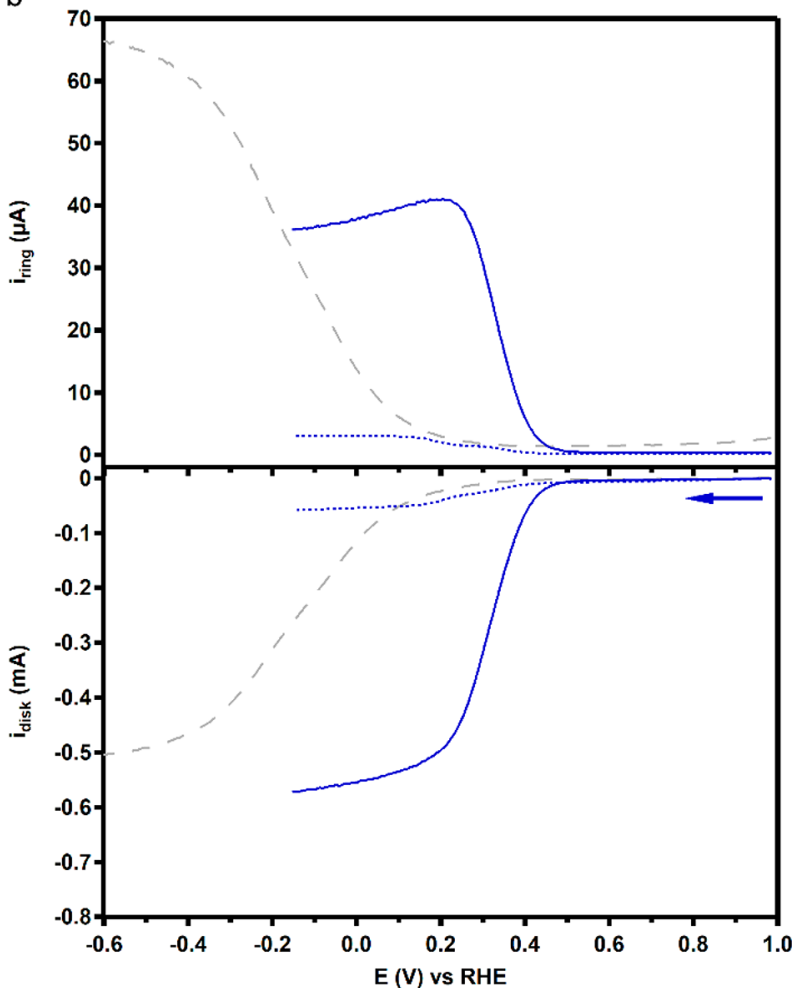

Figure 5. RRDE linear sweep voltammograms of $0.3 \mathrm{mM}$ Cu-terpy (a) and Cu-bmpa (b) under 1 atm $\mathrm{O}_{2}$ (solid lines) and 1 atm Ar (dotted lines) at $1600 \mathrm{rpm}$ as a function of applied disk potential. The reference voltammogram in the absence of complex under 1 atm $\mathrm{O}_{2}$ is depicted as a dashed gray line. Conditions: $0.1 \mathrm{M} \mathrm{pH} 7$ phosphate buffer, $293 \mathrm{~K}$, GC disk, Pt ring at $1.2 \mathrm{~V}$ vs RHE, $50 \mathrm{mV} \mathrm{s}^{-1}$ scan rate.

in good agreement with a diffusion controlled redox process (see Section 8 in the Supporting Information).

ORR Catalysis. The ORR behavior of Cu-terpy and $\mathrm{Cu}$ bmpa was investigated with $\mathrm{CV}$ in an aqueous $\mathrm{pH} 7$ buffered electrolyte under 1 atm $\mathrm{O}_{2}$ at a scan rate of $100 \mathrm{mV} \mathrm{s}^{-1}$. For these measurements, a GC WE was used. The electrolyte consisted of $0.1 \mathrm{M} \mathrm{pH} 7$ phosphate buffer for Cu-terpy and 0.1 M pH 7 HEPES buffered $\mathrm{NaClO}_{4}$ for Cu-bmpa. The ORR profile observed for both complexes shows a peak-shaped catalytic wave which is indicative of substrate depletion (Figure 4). ${ }^{52,53}$ Additionally, a relatively high half-wave potential of the catalytic wave $\left(E_{\text {cat } / 2}\right)$ is observed for both catalysts. $E_{\text {cat } / 2}$ is defined as the potential at which the catalytic wave reaches half its maximum current. Generally, half of the catalyst present near the electrode exists in its active form at this potential, which results in $E_{\text {cat } / 2}=E_{1 / 2} \cdot{ }^{54}$ For Cu-terpy and Cu-bmpa, $E_{\text {cat } / 2}$ amounts to 0.34 and $0.37 \mathrm{~V}$ vs RHE, respectively. Considering the $E_{1 / 2}$ of $0.31 \mathrm{~V}$ vs RHE for Cu-terpy and 0.30 $\mathrm{V}$ vs RHE for Cu-bmpa (vide supra), this results in $E_{\mathrm{cat} / 2}>E_{1 / 2}$ for both complexes. Just as reported for Cu-tmpa, ${ }^{37}$ this is also indicative of substrate depletion.

It is important to verify whether some Cu-terpy or $\mathbf{C u}$ bmpa material was left behind on the surface of the GC WE after contact with the $0.3 \mathrm{mM}$ catalyst solutions. For this purpose, various deposit checks were performed (see Section 9 in the Supporting Information). These experiments showed an enhanced catalytic activity which points to the presence of some deposit on the surface of the working electrode after one cyclic voltammetry scan in a $0.3 \mathrm{mM}$ solution of Cu-terpy or Cu-bmpa. This deposit proved to be less catalytically active for the ORR than the homogeneous catalyst dissolved in solution, validating that the first scan of each cyclic voltammetry measurement represents the behavior of the homogeneous system.

As shown in Figure S7, the ORR activity of $0.3 \mathrm{mM} \mathrm{Cu}$ bmpa in $0.1 \mathrm{M} \mathrm{pH} 7$ phosphate buffer is similar to the ORR activity observed in $0.1 \mathrm{M} \mathrm{pH} 7$ HEPES buffered $0.1 \mathrm{M}$ $\mathrm{NaClO}_{4}$. This means that the formation of a phosphate coordinated Cu-bmpa complex in the presence of phosphate buffer does not appear to affect the ORR behavior of this catalyst. However, taking into account potential issues with the presence of both HEPES and peroxide (see Section 16 in the Supporting Information), we carried out further catalytic experiments in phosphate buffer despite potential issues with phosphate coordination to copper.

ORR Product Selectivity. Rotating Ring Disk Electrode. In order to investigate the product selectivity of the ORR catalyzed by Cu-terpy and Cu-bmpa, a setup with a rotating ring disk electrode (RRDE) was used. Using this setup, the ORR occurs at a GC disk electrode. A Pt ring electrode is surrounding the GC disk and is set at a fixed potential of $1.2 \mathrm{~V}$ vs RHE. This potential is above the onset potential of $0.9 \mathrm{~V}$ vs RHE for $\mathrm{H}_{2} \mathrm{O}_{2}$ oxidation by $\mathrm{Pt}$ and below the onset potential of $1.5 \mathrm{~V}$ vs RHE for $\mathrm{H}_{2} \mathrm{O}$ oxidation by $\mathrm{Pt}$, both in $\mathrm{pH} 7$ phosphate buffer. ${ }^{55,56}$ This means that at this fixed ring potential of $1.2 \mathrm{~V}$ vs $\mathrm{RHE}, \mathrm{H}_{2} \mathrm{O}_{2}$ is oxidized whereas $\mathrm{H}_{2} \mathrm{O}$ is not, enabling determination of the product selectivity of the catalyzed ORR. Even though the RRDE setup is mostly used to study heterogeneous catalytic reactions, it can be used to study homogeneous catalytic reactions under certain conditions as well.

The main difficulty of employing RRDE methods for a homogeneous catalyst is that the substrate, the catalyst, and the product are all present in solution. For complex multistep 


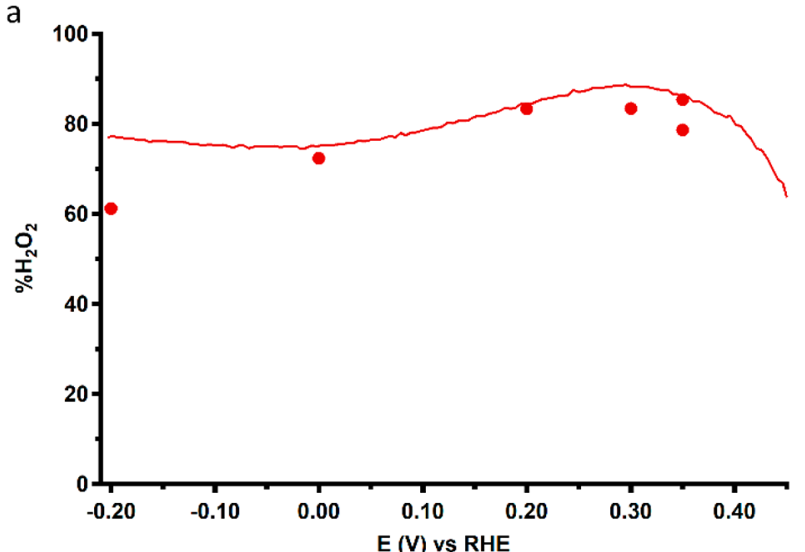

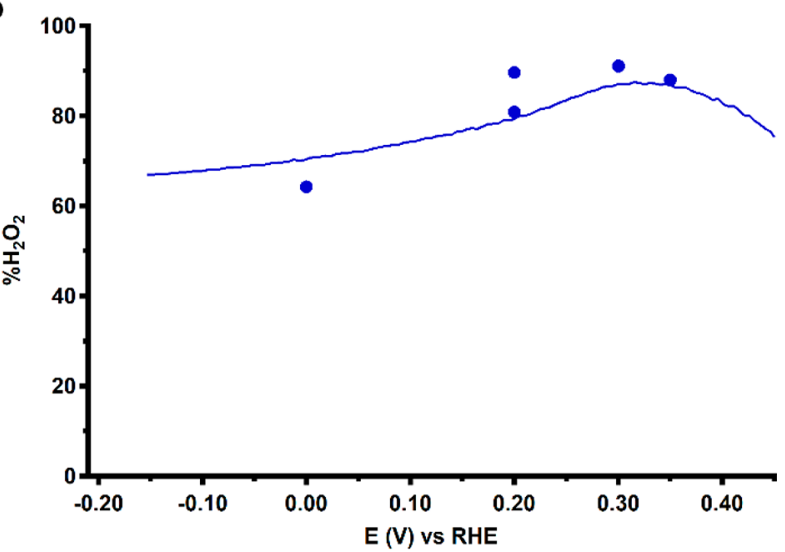

d

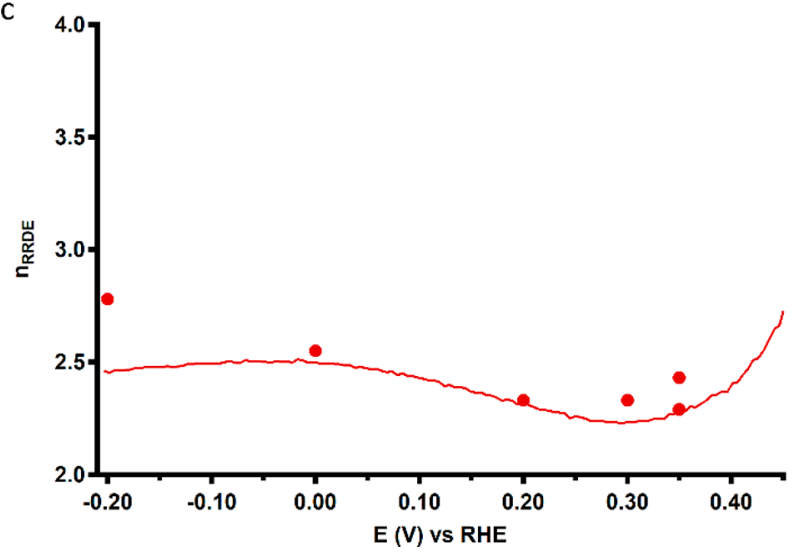

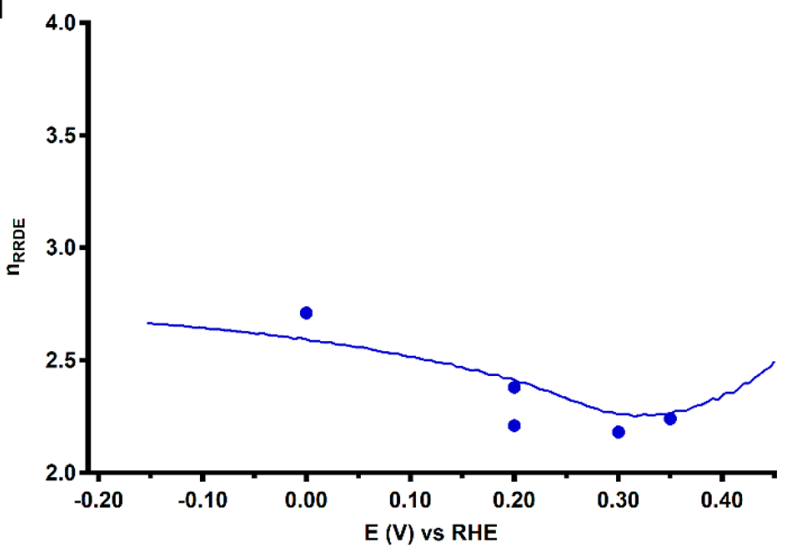

Figure 6. Percentage of $\mathrm{H}_{2} \mathrm{O}_{2}$ produced during ORR catalysis $\left(\% \mathrm{H}_{2} \mathrm{O}_{2}\right)$ and the associated electron transfer number $\left(n_{\mathrm{RRDE}}\right)$ obtained from RRDE LSV (lines, $50 \mathrm{mV} \mathrm{s}^{-1}$ ) and CA (dots) measurements as a function of applied disk potential for $0.3 \mathrm{mM}$ Cu-terpy and Cu-bmpa. Conditions: 0.1 $\mathrm{M} \mathrm{pH} 7$ phosphate buffer under $1 \mathrm{~atm} \mathrm{O}_{2}, 293 \mathrm{~K}$, GC disk, Pt ring at $1.2 \mathrm{~V}$ vs RHE, $1600 \mathrm{rpm}$.

multielectron reactions like the ORR, this results in the presence of more than one diffusing species in the liquid phase. For the ORR, these diffusing species comprise of the $\mathrm{Cu}^{\mathrm{II}}$ and $\mathrm{Cu}^{\mathrm{I}}$ state of the catalyst, the $\mathrm{O}_{2}$ substrate, the $\mathrm{Cu}^{\mathrm{II}}$-superoxide, $\mathrm{Cu}^{\mathrm{II}}$-hydroperoxo and $\mathrm{Cu}{ }^{\mathrm{II}}$-hydroxo adducts, and the $\mathrm{H}_{2} \mathrm{O}_{2}$ intermediate. Since these diffusing species can all reach the ring electrode, the true origin of the observed oxidizing ring current when it is set at a fixed potential of $1.2 \mathrm{~V}$ vs RHE should be established. This was done by studying the ring current when the ring electrode was set at a fixed potential below the onset potential for $\mathrm{H}_{2} \mathrm{O}_{2}$ oxidation by platinum.

The product selectivity of the ORR catalyzed by Cu-terpy and Cu-bmpa was studied in $0.1 \mathrm{M} \mathrm{pH} 7$ phosphate buffer for both catalysts. For this purpose, the RRDE setup was used to perform linear sweep voltammetry (LSV) at the GC disk and chronoamperometry (CA) at the $\mathrm{Pt}$ ring while rotating the RRDE at a speed of $1600 \mathrm{rpm}$ (Figure 5). LSV was performed between an upper potential limit of $1.0 \mathrm{~V}$ vs RHE and a lower potential limit of $-0.2 \mathrm{~V}$ vs RHE for Cu-terpy and $-0.15 \mathrm{~V}$ vs RHE for Cu-bmpa (see Section 11 in the Supporting Information for the reason for this difference in the lower potential limit), while CA was performed at $1.2 \mathrm{~V}$ vs RHE. Additional RRDE experiments with a ring potential set at $0.8 \mathrm{~V}$ vs RHE did not show any ring current, which indicates that no reduced catalytic species are being diffused toward and oxidized at the $\mathrm{Pt}$ ring electrode (Figure S9). Since the oxidation potential of both Cu-terpy and Cu-bmpa is located below $0.8 \mathrm{~V}$ vs RHE, the absence of ring current during the additional RRDE experiments illustrates that the observed ring current during ORR catalysis with a ring potential set at $1.2 \mathrm{~V}$ vs $\mathrm{RHE}$ corresponds to the oxidation of the formed $\mathrm{H}_{2} \mathrm{O}_{2}$ product only.

The ORR onset potential of the complexes has been defined in the context of the RRDE LSV measurements as the potential at which $i_{\mathrm{c}} / i_{\mathrm{GC}}>3$, in which $i_{\mathrm{c}}$ is the disk current observed during ORR catalysis performed by the catalyst and $i_{\mathrm{GC}}$ is the disk current observed in absence of the catalyst (Figure 5 bottom panels: solid lines vs dashed gray lines). For Cu-terpy and Cu-bmpa, this onset potential occurs at 0.45 and $0.49 \mathrm{~V}$ vs RHE, respectively. Considering the ORR onset potential of $0.50 \mathrm{~V}$ vs RHE for Cu-tmpa in $0.1 \mathrm{M} \mathrm{pH} 7$ phosphate buffer, ${ }^{37}$ the overpotential for the ORR catalyzed by $\mathbf{C u}$-terpy and $\mathbf{C u}$ bmpa is slightly higher than the ORR overpotential of $\mathbf{C u}$ tmpa. This is not in line with the higher $E_{1 / 2}$ values of 0.31 and $0.30 \mathrm{~V}$ vs RHE for Cu-terpy and Cu-bmpa, respectively, compared to the reported $E_{1 / 2}$ of $0.21 \mathrm{~V}$ vs RHE for $\mathbf{C u}$ tmpa. ${ }^{37}$

The RRDE LSV data of Cu-bmpa recorded under 1 atm Ar shows two cathodic events at the disk electrode and two anodic events at the ring electrode (Figure $5 b$ dotted line and zoom in Figure S4). This is in agreement with our earlier conclusion based on CV that some Cu-bmpa partly coordinates to phosphate in the presence of a phosphate buffer.

The RRDE LSV data of Cu-terpy and Cu-bmpa recorded under 1 atm $\mathrm{O}_{2}$ show maximum catalytic disk current $\left(i_{\text {cat }}\right)$ values of 0.66 and $0.57 \mathrm{~mA}$ at -0.20 and $-0.15 \mathrm{~V}$ vs RHE, respectively (Figure 5 ). These $i_{\text {cat }}$ values are substantially lower 


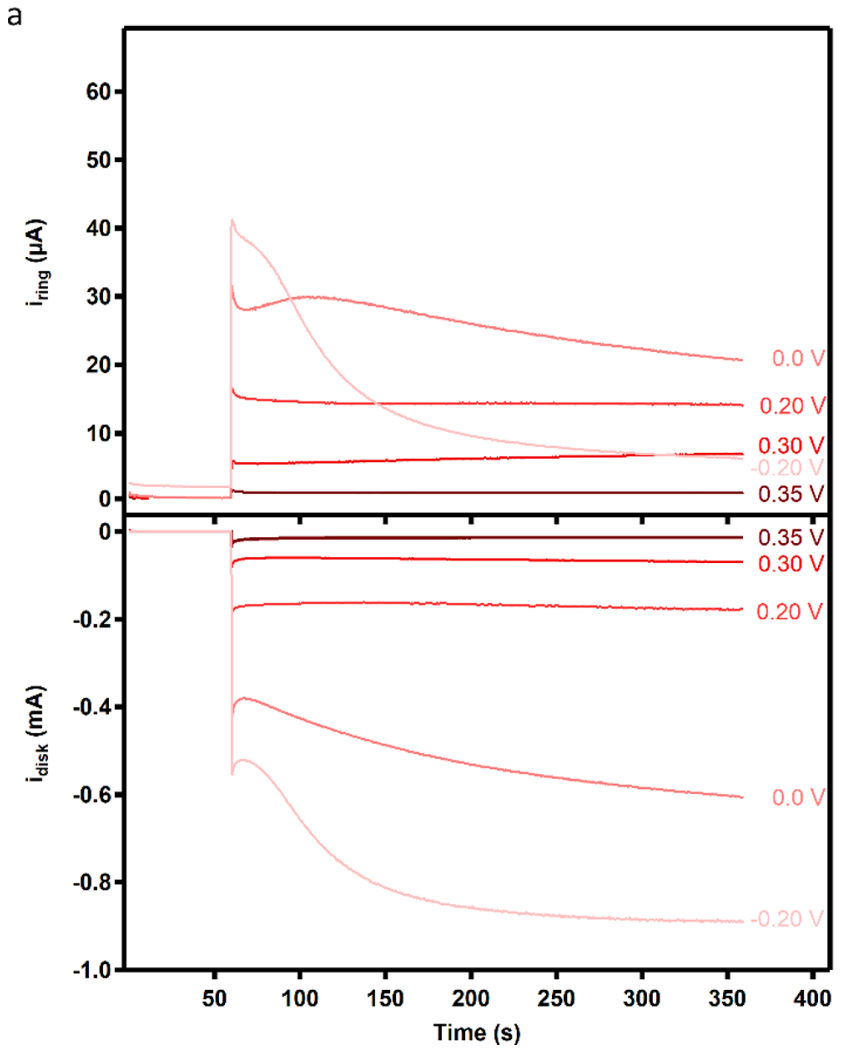

b

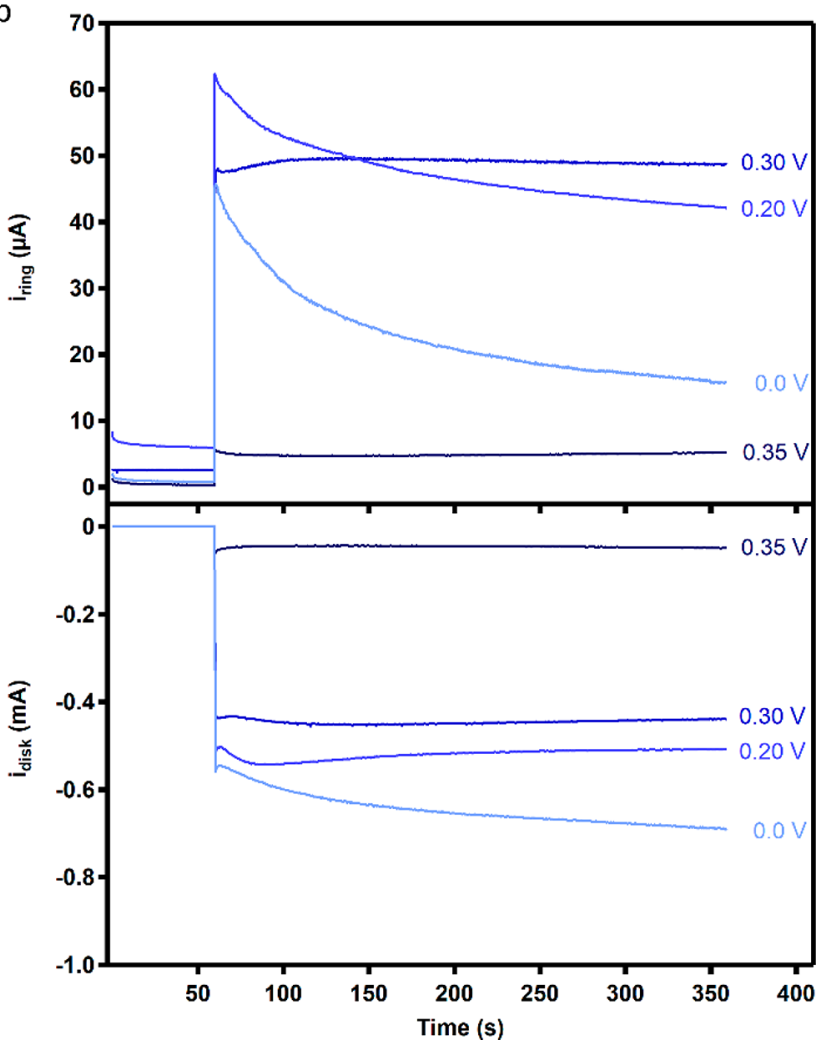

Figure 7. Disk and ring current responses for $0.3 \mathrm{mM} \mathrm{Cu}$-terpy (a) and Cu-bmpa (b) obtained during RRDE CA measurements as a function of time for various applied disk potentials. Each measurement is preceded by a background measurement at an applied disk potential of $0.8 \mathrm{~V}$ vs RHE for $1 \mathrm{~min}$. To prevent underestimation of $\% \mathrm{H}_{2} \mathrm{O}_{2}$ values and overestimation of $n_{\mathrm{RRDE}}$ values due to formation of a Cu deposit at low applied disk potential over time (see Section 13 in the Supporting Information), the resulting $\% \mathrm{H}_{2} \mathrm{O}_{2}$ and $n_{\text {RRDE }}$ values obtained from these RRDE CA measurements were averaged between 80 and 90 s. Conditions: $0.1 \mathrm{M} \mathrm{pH} 7$ phosphate buffer under $1 \mathrm{~atm} \mathrm{O}_{2}, 293 \mathrm{~K}, \mathrm{GC}$ disk, Pt ring at $1.2 \mathrm{~V}$ vs RHE, 1600 rpm.

than the reported $i_{\text {cat }}$ value of $\mathbf{C u}$-tmpa obtained at a rotation speed of $1600 \mathrm{rpm}$ which amounts to $0.99 \mathrm{~mA}$ at potentials below $0.15 \mathrm{~V}$ vs RHE. ${ }^{37}$ However, significantly higher ring currents were detected in the case of Cu-terpy and Cu-bmpa compared to Cu-tmpa, indicating that substantial amounts of hydrogen peroxide are formed. Especially the absence of a significant ring current during both the RRDE LSV data recorded under $1 \mathrm{~atm} \mathrm{Ar}$ (Figure 5 dotted lines) and under 1 atm $\mathrm{O}_{2}$ with a ring potential set at $0.8 \mathrm{~V}$ vs RHE (Figure S9) indicates that the ring current observed during ORR catalysis is the result of hydrogen peroxide formation and not due to diffusion of a reduced catalytic species toward the ring electrode. Since the formation of $\mathrm{H}_{2} \mathrm{O}_{2}$ is associated with a two-electron reduction as opposed to the four-electron reduction for the formation of water, the formation of $\mathrm{H}_{2} \mathrm{O}_{2}$ is associated with a lower catalytic disk current.

Quantification of $\mathrm{H}_{2} \mathrm{O}_{2}$. To quantify the formation of $\mathrm{H}_{2} \mathrm{O}_{2}$ along the potential regime for ORR catalysis, the percentage of $\mathrm{H}_{2} \mathrm{O}_{2}$ produced during ORR catalysis $\left(\% \mathrm{H}_{2} \mathrm{O}_{2}\right)$ and the associated electron transfer number $\left(n_{\mathrm{RRDE}}\right)$ were determined according to eqs 1 and 2, respectively

$$
\begin{aligned}
& \% \mathrm{H}_{2} \mathrm{O}_{2}=\frac{2 \times\left(i_{\text {ring }} / \mathrm{N}_{\mathrm{H}_{2} \mathrm{O}_{2}}\right)}{i_{\text {disk }}+\left(i_{\text {ring }} / N_{\mathrm{H}_{2} \mathrm{O}_{2}}\right)} \times 100 \% \\
& n_{\mathrm{RRDE}}=\frac{4 \times i_{\text {disk }}}{i_{\text {disk }}+\left(i_{\text {ring }} / N_{\mathrm{H}_{2} \mathrm{O}_{2}}\right)}
\end{aligned}
$$

where $i_{\text {ring }}$ and $i_{\text {disk }}$ are the observed ring and disk current, respectively, and $\mathrm{N}_{\mathrm{H}_{2} \mathrm{O}_{2}}$ is the collection efficiency of the Pt ring for $\mathrm{H}_{2} \mathrm{O}_{2} \cdot{ }^{57}$ In a previous publication, we showed that this collection efficiency amounts to 0.125 for the same RRDE setup. $^{37}$

Figure 6 shows the $\% \mathrm{H}_{2} \mathrm{O}_{2}$ and $n_{\mathrm{RRDE}}$ values along the potential regime for ORR catalysis of $\mathbf{C u}$-terpy and Cu-bmpa obtained from the RRDE LSV data (red and blue lines). For Cu-terpy, the percentage of $\mathrm{H}_{2} \mathrm{O}_{2}$ produced during ORR catalysis increases from $\sim 60 \%$ near the ORR onset potential to $\sim 80 \%$ at the lower potential limit with a maximum of $\sim 90 \%$ at $0.3 \mathrm{~V}$ vs RHE (Figure 6a). For Cu-bmpa, the initial $\% \mathrm{H}_{2} \mathrm{O}_{2}$ of $\sim 75 \%$ near the ORR onset potential decreases to $\sim 70 \%$ at the lower potential limit with a maximum of $\sim 90 \%$ at $0.3 \mathrm{~V}$ vs RHE as well (Figure 6b). The high Faradaic efficiencies for $\mathrm{H}_{2} \mathrm{O}_{2}$ production observed at low applied disk potential agree with the observed lower maximum catalytic disk currents for the ORR catalyzed by Cu-terpy and Cu-bmpa compared to Cu-tmpa. The $n_{\mathrm{RRDE}}$ values obtained from the RRDE LSV data indicate a slight decrease from $\sim 2.7$ to $\sim 2.5$ for Cu-terpy and a slight increase from $\sim 2.5$ to $\sim 2.7$ for Cu-bmpa. This trend observed for the electron transfer number reflects the inverse trend observed for the $\% \mathrm{H}_{2} \mathrm{O}_{2}$ values, since a decrease in production of $\mathrm{H}_{2} \mathrm{O}_{2}(n=2)$ is associated with an increase in production of $\mathrm{H}_{2} \mathrm{O}(n=4)$ and vice versa. Noteworthy, a contribution of the $\mathrm{GC}$ disk toward $\mathrm{H}_{2} \mathrm{O}_{2}$ production cannot be excluded below $0.1 \mathrm{~V}$ vs RHE (Figure 5 dashed gray lines). 

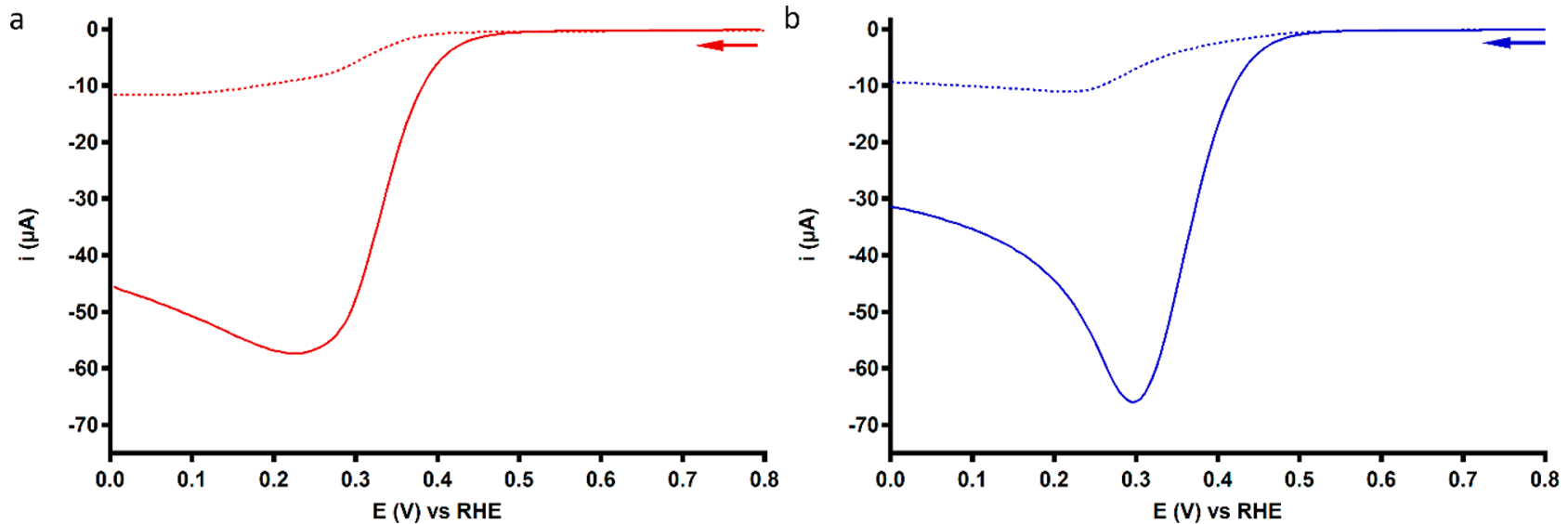

Figure 8. Linear sweep voltammograms of the reduction of 1 atm $\mathrm{O}_{2}$ (solid lines) and $1.1 \mathrm{mM} \mathrm{H}_{2} \mathrm{O}_{2}$ under 1 atm $\mathrm{Ar}$ (dotted lines) catalyzed by 0.3 $\mathrm{mM}$ Cu-terpy in $0.1 \mathrm{M} \mathrm{pH} 7$ phosphate buffer (a) and $0.3 \mathrm{mM} \mathrm{Cu}$-bmpa in $0.1 \mathrm{M} \mathrm{pH} 7$ HEPES buffered $0.1 \mathrm{M} \mathrm{NaClO}_{4}$ (b). Conditions: $293 \mathrm{~K}$, GC WE, $100 \mathrm{mV} \mathrm{s}^{-1}$ scan rate.

Additionally, the values for $\% \mathrm{H}_{2} \mathrm{O}_{2}$ and $n_{\mathrm{RRDE}}$ were determined by RRDE CA measurements as a function of time. These RRDE CA measurements were performed at an applied disk potential of $0.35,0.30,0.20$, and $0.0 \mathrm{~V}$ vs RHE for 5 min and additionally at $-0.20 \mathrm{~V}$ vs RHE for $5 \mathrm{~min}$ for $\mathbf{C u}$ terpy (Figure 7). A duplicate RRDE CA measurement was performed at $0.35 \mathrm{~V}$ vs RHE for Cu-terpy and at $0.20 \mathrm{~V}$ vs $\mathrm{RHE}$ for Cu-bmpa. As shown in Figure 6, the $\% \mathrm{H}_{2} \mathrm{O}_{2}$ values obtained from the RRDE CA data correlate well with the values obtained from the RRDE LSV data.

During the RRDE CA measurements performed at an applied disk potential of 0.0 and $-0.20 \mathrm{~V}$ vs RHE for Cu-terpy, the current responses did not stabilize (Figure 7). Instead, the disk current increases and the ring current decreases over time at these applied potentials. A similar effect is observed for $\mathbf{C u}$ bmpa at an applied disk potential of $0.0 \mathrm{~V}$ vs RHE, whereas at $0.20 \mathrm{~V}$ vs RHE the ring current decreases over time while the disk current stabilizes. The mismatch between the disk and ring current responses indicates that the selectivity of the ORR changes over time at these low applied disk potentials. This phenomenon appears to start at a slightly higher potential for Cu-bmpa than for Cu-terpy. A deposit study performed for Cu-bmpa after the RRDE CA measurements indicates that the change in selectivity of the ORR is the result of the formation of a $\mathrm{Cu}^{0}$ deposit at low applied disk potential (see Section 13 in the Supporting Information). Additional RRDE CA measurements performed at $0.35 \mathrm{~V}$ vs RHE for $40 \mathrm{~min}$ indicate that the disk and ring current responses of Cu-terpy and Cu-bmpa are stable upon prolonged cathodic exposure at slightly higher applied disk potentials (Figure S12).

In addition to quantification of the $\mathrm{H}_{2} \mathrm{O}_{2}$ formation during ORR catalysis with the aid of the RRDE setup, the Faradaic efficiency of $\mathbf{C u}$-terpy and $\mathbf{C u}$-bmpa for $\mathrm{H}_{2} \mathrm{O}_{2}$ production was also determined by measuring the concentration of $\mathrm{H}_{2} \mathrm{O}_{2}$ present in the electrolyte after performing bulk ORR catalysis at $0.20 \mathrm{~V}$ vs RHE for $5 \mathrm{~min}$ (see Section 15 in the Supporting Information). The $\mathrm{H}_{2} \mathrm{O}_{2}$ concentration was determined with a peroxidase-based photometric measurement (see Section 1.4.5 in the Supporting Information for the experimental details). The obtained absolute concentration of $\mathrm{H}_{2} \mathrm{O}_{2}$ after performing $\mathrm{RDE} C A$ at $0.20 \mathrm{~V}$ vs RHE for $5 \mathrm{~min}$ amounted to (0.022 \pm $0.001) \mathrm{mM}$ for Cu-terpy and $(0.030 \pm 0.001) \mathrm{mM}$ for $\mathbf{C u}$ bmpa in $15 \mathrm{~mL}$ electrolyte. Comparison of the expected charge buildup for these amounts of produced $\mathrm{H}_{2} \mathrm{O}_{2}$ with the observed charge buildup during the $5 \mathrm{~min} \mathrm{RDE} \mathrm{CA}$ measurement results in a Faradaic efficiency for $\mathrm{H}_{2} \mathrm{O}_{2}$ production of $(72 \pm 2) \%$ for Cu-terpy and $(72 \pm 3) \%$ for Cu-bmpa. These values are slightly lower than the $\% \mathrm{H}_{2} \mathrm{O}_{2}$ values determined by RRDE LSV and RRDE CA measurements at $0.20 \mathrm{~V}$ vs RHE for both catalysts (Figure 6). This is the result of the smaller amount of electrolyte which was used during the RDE CA measurements $(15 \mathrm{~mL}$ vs $50 \mathrm{~mL}$ for RRDE LSV and RRDE CA), resulting in an increase of the $\mathrm{H}_{2} \mathrm{O}_{2}$ concentration and therefore more reduction of $\mathrm{H}_{2} \mathrm{O}_{2}$ to $\mathrm{H}_{2} \mathrm{O}$. The obtained $\mathrm{H}_{2} \mathrm{O}_{2}$ concentrations and therefore the Faradaic efficiencies are the average of six measurements and are reported with the standard error.

$\mathrm{H}_{2} \mathrm{O}_{2}$ Reduction Behavior. As discussed above, the RRDE LSV data of both Cu-terpy and Cu-bmpa result in relatively high $\% \mathrm{H}_{2} \mathrm{O}_{2}$ and low $n_{\mathrm{RRDE}}$ values along the entire potential window for ORR catalysis (Figure 6). This means that both catalysts do not catalyze the full four-electron ORR $\left(n_{\mathrm{RRDE}}=\right.$ 4) in the investigated potential window. Considering that $n_{\text {RRDE }}$ is larger than two along the ORR active potential window of both catalysts, limitations seem to arise after the initial two-electron reduction of $\mathrm{O}_{2}$ to $\mathrm{H}_{2} \mathrm{O}_{2}$. Therefore, the $\mathrm{H}_{2} \mathrm{O}_{2}$ reduction behavior of both Cu-terpy and Cu-bmpa was investigated by performing LSV under $1 \mathrm{~atm} \mathrm{Ar}$ in a $0.3 \mathrm{mM}$ catalyst solution in $\mathrm{pH} 7$ buffered electrolyte containing $\mathrm{H}_{2} \mathrm{O}_{2}$ (Figure 8 dotted lines). The $\mathrm{H}_{2} \mathrm{O}_{2}$ concentration amounted to $1.1 \mathrm{mM}$ in order to reproduce the concentration of $\mathrm{O}_{2}$ in an $\mathrm{O}_{2}$ saturated $\mathrm{pH} 7$ buffered electrolyte under 1 atm $\mathrm{O}_{2}$ which was used during ORR catalysis. ${ }^{58-60}$ Just like for the stationary ORR catalysis measurements, the electrolyte during the stationary $\mathrm{H}_{2} \mathrm{O}_{2}$ reduction measurements consisted of $0.1 \mathrm{M}$ pH 7 phosphate buffer for Cu-terpy and 0.1 M pH 7 HEPES buffered $\mathrm{NaClO}_{4}$ for Cu-bmpa.

The $\mathrm{H}_{2} \mathrm{O}_{2}$ reduction profile observed for Cu-terpy and $\mathbf{C u}$ bmpa does not show a clear peak-shaped catalytic wave as observed for the ORR behavior (Figure 8). Instead, an Sshaped catalytic wave is observed. This represents catalysis that does not involve a change in substrate concentration, indicating that substrate depletion is not taking place during $\mathrm{H}_{2} \mathrm{O}_{2}$ reduction. ${ }^{52,53,61}$ The absence of substrate depletion confirms that the $\mathrm{H}_{2} \mathrm{O}_{2}$ reduction activity of both catalysts is low and indeed the limiting factor during ORR catalysis. In contrast, a peak-shaped catalytic wave indicative of substrate depletion and therefore high catalytic activity has been 
reported for $\mathrm{H}_{2} \mathrm{O}_{2}$ reduction catalysis performed by $\mathbf{C u}$ tmpa. 37

The $\mathrm{H}_{2} \mathrm{O}_{2}$ reduction onset potential of the complexes has been determined by RDE LSV measurements in $0.1 \mathrm{M} \mathrm{pH} 7$ phosphate buffer and is defined in this context as the potential at which $i_{\mathrm{c}} / i_{\mathrm{GC}}>2$, in which $i_{\mathrm{c}}$ is the current observed during $\mathrm{H}_{2} \mathrm{O}_{2}$ reduction catalysis performed by the catalyst (see Section 16 in the Supporting Information) and $i_{\mathrm{GC}}$ is the disk current observed during ORR catalysis in the absence of the catalyst (Figure 5 dashed gray lines in bottom panels). For $\mathbf{C u}$ terpy and Cu-bmpa, this onset potential is located at 0.31 and $0.42 \mathrm{~V}$ vs RHE, respectively. These onset potentials observed for $\mathrm{H}_{2} \mathrm{O}_{2}$ reduction are lower than the corresponding onset potentials for ORR catalysis of 0.45 and $0.49 \mathrm{~V}$ vs RHE, respectively. After performing the $\mathrm{H}_{2} \mathrm{O}_{2}$ reduction RDE LSV measurement for Cu-bmpa in 0.1 M pH 7 HEPES buffered 0.1 $\mathrm{M} \mathrm{NaClO}$ 4 electrolyte, the color of the catalyst solution changed over time from light blue to light yellow (see Section 17 in the Supporting Information).

Catalytic Rate. The TOF for the partial reduction of $\mathrm{O}_{2}$ to $\mathrm{H}_{2} \mathrm{O}_{2}$ can be determined by the foot-of-the-wave analysis (FOWA). The FOWA was introduced by Savéant et al. as a method to determine the TOF for heterogeneous and homogeneous electrocatalysts. ${ }^{61}$ The method excludes side phenomena like substrate consumption, catalyst deactivation, and product inhibition by only considering the onset region of the catalytic wave observed during a standard CV measurement. At this region, catalysis is considered to take place under kinetic conditions. Since substrate consumption does play an important role during the ORR due to limitations in $\mathrm{O}_{2}$ concentration, the FOWA is an excellent tool to study the ORR in more depth. Considering the lower onset potential observed for the $\mathrm{H}_{2} \mathrm{O}_{2}$ reduction reaction compared to the ORR for both Cu-terpy and Cu-bmpa (vide supra), the amount of $\mathrm{H}_{2} \mathrm{O}_{2}$ reduced in solution at the foot of the catalytic wave is limited. This results in a $\mathrm{H}_{2} \mathrm{O}_{2}$ reduction rate which is negligible compared to the rate for the two-electron reduction of $\mathrm{O}_{2}$ at this onset region. Therefore, the FOWA results in the TOF associated with the partial reduction of $\mathrm{O}_{2}$ to $\mathrm{H}_{2} \mathrm{O}_{2}$ (TOF). Noteworthy, this TOF is in fact the theoretical maximum TOF for $\mathrm{O}_{2}$ to $\mathrm{H}_{2} \mathrm{O}_{2}$ reduction $\left(\mathrm{TOF}_{\max }\right.$ ), as the FOWA excludes the experimental limitation of $\mathrm{O}_{2}$ diffusion due to substrate consumption. Furthermore, it is assumed that the reported fast ligand exchange kinetics of copper results in fast exchange of the formed $\mathrm{H}_{2} \mathrm{O}_{2}$ intermediate with $\mathrm{H}_{2} \mathrm{O}$ originating from the electrolyte solution, which means that the intermediate is not immediately further reduced to produce water as the four-electron product of the ORR. ${ }^{62}$ Electrochemical quartz crystal microbalance (EQCM) experiments (see Section 18 in the Supporting Information) indicate that over time Cu-terpy accumulates at the working electrode at negative potentials and under conditions where on the basis of selectivity no $\mathrm{Cu}^{0}$ is expected yet. However, these effects appear to be minimal in the potential domain where the FOWA is carried out.

To determine the $\mathrm{TOF}_{\max }$ for the partial reduction of $\mathrm{O}_{2}$ to $\mathrm{H}_{2} \mathrm{O}_{2}$, the FOWA was applied to the ORR profile that was obtained by stationary CV (Figure 4). However, to be able to apply the FOWA correctly to the obtained catalytic data, the rate law of the two-electron ORR has to be obtained. Both the binding of $\mathrm{O}_{2}$ to $\mathrm{Cu}$-tmpa and the ORR catalyzed by Cu-tmpa have previously been shown by Karlin et al. to involve a dimerization step in organic solvent. ${ }^{27,36,38-40}$ However, as recently indicated by our group, ORR catalysis performed by Cu-tmpa in aqueous $\mathrm{pH} 7$ buffered solution proceeds via reactions at mononuclear species that are significantly faster than the formation of $\mu$ - $\left(\mathrm{O}_{2}\right)$-bridged dimers. ${ }^{37}$ For Cu-terpy and Cu-bmpa, a mononuclear mechanism is also expected for ORR catalysis in $\mathrm{pH} 7$ buffered aqueous solution, since significant catalytic ORR activity was still observed for both species at micromolar catalyst concentration (see Section 19 in the Supporting Information). The first order mechanism in catalyst for the two-electron ORR catalyzed by both Cu-terpy and Cu-bmpa is supported by a poor linear fit of the FOWA for a second order relationship in catalyst (see Section 22 in the Supporting Information). It is therefore expected that both Cu-terpy and Cu-bmpa follow the same initial elemental steps during ORR catalysis as described for Cu-tmpa in aqueous $\mathrm{pH}$ 7 buffered solution. ${ }^{37}$ These elemental steps are as follows:

$$
\begin{aligned}
& \mathrm{Cu}^{\mathrm{II}}+\mathrm{e}^{-} \rightleftharpoons \mathrm{Cu}^{\mathrm{I}} \quad E_{\mathrm{Cu}^{\mathrm{I} / \mathrm{I}}} \\
& \mathrm{Cu}^{\mathrm{I}}+\mathrm{O}_{2} \rightarrow \mathrm{Cu}^{\mathrm{II}} \mathrm{O}_{2}^{\bullet-} \quad k_{1}=k_{\mathrm{O}_{2}} \\
& \mathrm{Cu}^{\mathrm{II}} \mathrm{O}_{2}^{\bullet-}+\mathrm{H}^{+}+\mathrm{e}^{-} \rightarrow \mathrm{Cu}^{\mathrm{II}} \mathrm{OOH} \quad k_{2}
\end{aligned}
$$

The presence of the $\mathrm{pH} 7$ buffered solution ensures that the maximum catalytic current does not depend on the proton concentration during the electrochemical measurements. Therefore, a catalytic system in which the first chemical step following the reduction of the catalyst is rate determining can be assumed. This means that $k_{\text {obs }}$ is only limited by $\mathrm{O}_{2}$ binding, resulting in $k_{\mathrm{obs}}=k_{\mathrm{O}_{2}}\left[\mathrm{O}_{2}\right]$. For a multistep catalytic process in which the first chemical step following the reduction of the catalyst is rate determining, the catalytic current response can be described as a function of the potential according to eq 3 :

$$
i_{\mathrm{c}}=\frac{n F A C_{\mathrm{cat}}^{0} \sqrt{D_{\mathrm{cat}} k_{\mathrm{obs}}}}{1+\exp \left[\frac{F}{R T}\left(E-E_{1 / 2}\right)\right]}
$$

In this equation, $i_{c}$ is the observed catalytic current in $A, E_{1 / 2}$ is the half-wave potential of the catalyst's $\mathrm{Cu}^{\mathrm{II}} / \mathrm{Cu}^{\mathrm{I}}$ redox couple, and $k_{\mathrm{obs}}$ is the observed rate constant with $k_{\mathrm{obs}}=$ TOF $_{\text {max }}{ }^{61,63}$ Noteworthy, all electron transfer steps are considered to occur at the electrode surface in this currentpotential approximation, without any homogeneous electron transfer taking place between species. Normalization of eq 3 with the observed peak current of the one-electron reduction of the catalyst $\left(i_{\text {p,red }}\right)$ using the Randles-Sevcik eq 1 results in eq 4 (see Section 20 in the Supporting Information):

$$
\frac{i_{\mathrm{c}}}{i_{\mathrm{p}, \text { red }}}=\frac{2.24 n \sqrt{\frac{R T}{F v} k_{\mathrm{obs}}}}{1+\exp \left[\frac{F}{R T}\left(E-E_{1 / 2}\right)\right]}
$$

In this equation, $n$ is the number of electrons involved in the catalytic cycle. Since only the partial reduction of $\mathrm{O}_{2}$ to $\mathrm{H}_{2} \mathrm{O}_{2}$ is considered during the FOWA, $n$ equals 2 in this specific case. Applying eq 4, the $\mathrm{TOF}_{\max }$ of the two-electron reduction of $\mathrm{O}_{2}$ to $\mathrm{H}_{2} \mathrm{O}_{2}$ can be determined via the slope of the $i_{\mathrm{c}} / i_{\mathrm{p} \text {,red }}$ vs $1 /\left(1+\exp \left[\frac{F}{R T}\left(E-E_{1 / 2}\right)\right]\right)$ plot (Figure S19a,b). A linear fit was obtained between the onset potential of the ORR and 0.40 $\mathrm{V}$ vs RHE for Cu-terpy (Figure S19c) and between the onset potential of the ORR and $0.42 \mathrm{~V}$ vs RHE for Cu-bmpa (Figure S19d). Averaging of the resulting $\mathrm{TOF}_{\max }$ values over three individual ORR measurements resulted in a $\mathrm{TOF}_{\max }$ for the 
partial reduction of $\mathrm{O}_{2}$ to $\mathrm{H}_{2} \mathrm{O}_{2}$ of $(3.0 \pm 0.6) \cdot 10^{2} \mathrm{~s}^{-1}$ for $\mathbf{C u}$ terpy and $(2.4 \pm 1.9) \cdot 10^{4} \mathrm{~s}^{-1}$ for Cu-bmpa, both in $\mathrm{pH} 7$ buffered electrolyte and reported with the standard error. Compared to the reported TOF $_{\max }$ of $(1.8 \pm 0.6) \cdot 10^{6} \mathrm{~s}^{-1}$ for the partial reduction of $\mathrm{O}_{2}$ to $\mathrm{H}_{2} \mathrm{O}_{2}$ catalyzed by $\mathrm{Cu}$-tmpa in $0.1 \mathrm{M}$ pH 7 phosphate buffer, ${ }^{37}$ the TOF $_{\max }$ for $\mathrm{O}_{2}$ to $\mathrm{H}_{2} \mathrm{O}_{2}$ reduction catalyzed by Cu-terpy and Cu-bmpa is 4 and 2 orders of magnitude smaller, respectively.

Origin of Relatively Low TOF. As mentioned in the EPR spectroscopy section in the Supporting Information, $\mathrm{Cu}^{\mathrm{II}}$ centers generally adopt a distorted octahedral, square pyramidal, square planar, or trigonal bipyramidal coordination geometry. In contrast, $\mathrm{Cu}^{\mathrm{I}}$ centers favor a tetrahedral coordination geometry. ${ }^{64}$ This difference in preferred coordination geometry for the $+\mathrm{I}$ and $+\mathrm{II}$ oxidation states of copper can result in large reorganization barriers during electron transfer. As indicated by the crystal structure of Cu-terpy (Figure S3) and the EPR data of Cu-bmpa (see Section 3 in the Supporting Information), the $\mathrm{Cu}^{\mathrm{II}}$ state of these complexes adopts an octahedral geometry and an elongated octahedral, square pyramidal, or square planar geometry, respectively. Upon reduction to the $\mathrm{Cu}^{\mathrm{I}}$ state, the rigidity of the terpy ligand prevents formation of the preferred tetrahedral coordination geometry for a $\mathrm{Cu}^{\mathrm{I}}$ complex. In contrast, the reported trigonal bipyramidal geometry of $[\mathrm{Cu}(\mathrm{tmpa})(\mathrm{MeCN})]^{+}$has been shown to possess an elongated $\mathrm{Cu}-\mathrm{N}_{\text {amine }}$ bond compared to $[\mathrm{Cu}(\mathrm{tmpa})(\mathrm{MeCN})]^{2+}$. ${ }^{65}$ The elongation from 2.10 to $2.43 \AA$ upon reduction of the copper center suggests that formation of the preferred tetrahedral coordination geometry for a $\mathrm{Cu}^{\mathrm{I}}$ complex can occur for Cu-tmpa by dissociation of the tertiary amine (Figure 9a). Even though the bmpa ligand of Cu-bmpa

a

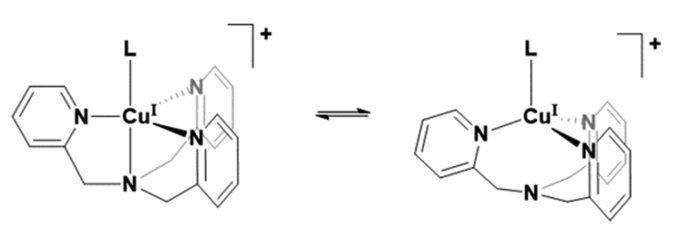

b

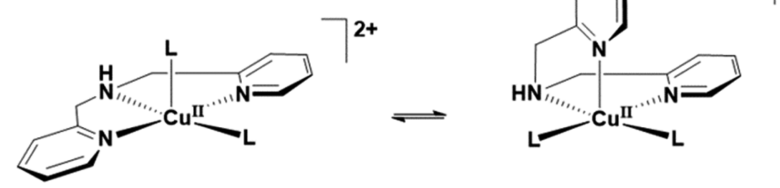

Figure 9. a) Hypothesized formation of the preferred tetrahedral geometry for a $\mathrm{Cu}^{\mathrm{I}}$ complex by dissociation of the tertiary amine of $[\mathrm{Cu}(\mathrm{tmpa})(\mathrm{L})]^{+}$. b) Conversion from a meridional to a facial orientation of the bmpa ligand in Cu-bmpa.

can relatively easily convert from a meridional to a facial orientation (Figure 9b), ${ }^{66}$ this conversion does not result in a tetrahedral geometry. As a result of the difference in ability to form the preferred tetrahedral coordination geometry for a $\mathrm{Cu}^{\mathrm{I}}$ complex, a higher energetic barrier for the formation of the $\mathrm{Cu}^{\mathrm{I}}$ state of the complex is expected for Cu-terpy and Cu-bmpa compared to Cu-tmpa. However, as mentioned in the ORR catalysis section, the $E_{1 / 2}$ values of $\mathbf{C u}$-terpy and Cu-bmpa are shifted positively by 0.10 and $0.09 \mathrm{~V}$ vs RHE, respectively, compared to the reported $E_{1 / 2}$ of $0.21 \mathrm{~V}$ vs RHE for $\mathbf{C u}$ tmpa. ${ }^{37}$ These positive shifts correspond to a thermodynami- cally more favorable reduction to the $\mathrm{Cu}^{\mathrm{I}}$ state of the complex for Cu-terpy and Cu-bmpa than for Cu-tmpa.

The absence of a fourth binding arm for the terpy and bmpa ligands with respect to the tmpa ligand suggests that the electron donating ability is lower for terpy and bmpa. Correspondingly, the poor electron donating ability might cause the thermodynamically less favorable reoxidation of the $\mathrm{Cu}^{\mathrm{I}}$ state of $\mathbf{C u}$-terpy and Cu-bmpa to the $\mathrm{Cu}^{\mathrm{II}}$ state, which was indicated by the slow electron transfer kinetics for this anodic event (see Laviron plots in Figure 3). The difference between the scan rate at which the $\mathrm{Cu}^{\mathrm{II}} / \mathrm{Cu}^{\mathrm{I}}$ redox couple of Cu-terpy and Cu-bmpa is still reversible $\left(10 \mathrm{mV} \mathrm{s}^{-1}\right.$ for $\mathbf{C u}$ terpy and $100 \mathrm{mV} \mathrm{s}^{-1}$ for Cu-bmpa) indicates that the electron transfer kinetics of the anodic event is faster for $\mathbf{C u}$ bmpa than for Cu-terpy.

As mentioned for the determination of the $\mathrm{TOF}_{\max }$ (vide supra), the formation of the $\mathrm{Cu}^{\mathrm{II}}$-superoxide adduct is expected to be the rate-determining step during ORR catalysis performed by $\mathbf{C u}$-terpy and Cu-bmpa. Overall, the increasing electron donating ability along terpy $<$ bmpa $<$ tmpa results in a decrease of the barrier between the $\mathrm{Cu}^{\mathrm{I}}$ state of the complex and the $\mathrm{Cu}^{\mathrm{II}}$-superoxide adduct along Cu-terpy > Cu-bmpa > Cu-tmpa. Additionally, the increasing ability to form the preferred tetrahedral coordination geometry for a $\mathrm{Cu}^{\mathrm{I}}$ complex along Cu-terpy $<$ Cu-bmpa $<$ Cu-tmpa results in the observed increase in electron transfer kinetics for the redox behavior along the same trend and correspondingly more rapid formation of the active ORR catalyst. The lower $\mathrm{TOF}_{\max }$ of $(3.0 \pm 0.6) \cdot 10^{2}$ and $(2.4 \pm 1.9) \cdot 10^{4} \mathrm{~s}^{-1}$ obtained for $\mathrm{O}_{2}$ to $\mathrm{H}_{2} \mathrm{O}_{2}$ reduction by $\mathrm{Cu}$-terpy and $\mathrm{Cu}$-bmpa, respectively, compared to a $\mathrm{TOF}_{\max }$ of $(1.8 \pm 0.6) \cdot 10^{6} \mathrm{~s}^{-1}$ reported for $\mathrm{Cu}$ tmpa, ${ }^{37}$ indicates that the ORR activity increases along $\mathbf{C u}$ terpy $<$ Cu-bmpa $<$ Cu-tmpa. This is clearly in line with both the decrease of the barrier between the $\mathrm{Cu}^{\mathrm{I}}$ and $\mathrm{Cu}^{\mathrm{II}}$ states of the complex and the increase in electron transfer kinetics of the redox couple.

\section{CONCLUSION}

Cu-tmpa has been shown to be a more active catalyst for the ORR than Cu-terpy and Cu-bmpa. Our data shows that this trend in activity is also observed for the electron transfer kinetics of the $\mathrm{Cu}^{\mathrm{I}} / \mathrm{Cu}^{\mathrm{II}}$ redox couples. Laviron plots of all three complexes show that electron transfer rates are relatively slow in the case of Cu-terpy and Cu-bmpa compared to $\mathbf{C u}$ tmpa. ${ }^{37}$ The underlying phenomenon is the reorganization energy that must be overcome to convert tetrahedral $\mathrm{Cu}^{\mathrm{I}}$ into nontetrahedral $\mathrm{Cu}^{\mathrm{II}}$, which is most facile in the case of $\mathbf{C u}$ tmpa which can easily decoordinate one of its four $\mathrm{N}$-donors. It can therefore be concluded that both the tetradentate nature of the tmpa ligand and the ability of Cu-tmpa to form the preferred tetrahedral coordination geometry for a $\mathrm{Cu}^{\mathrm{I}}$ complex are of utmost importance for the great success of the Cu-tmpa catalyzed ORR.

In addition, the use of the tetradentate tmpa ligand also is beneficial in terms of catalyst stability and product selectivity. However, the high Faradaic efficiencies observed for $\mathrm{H}_{2} \mathrm{O}_{2}$ production along the ORR active potential window of $\mathbf{C u}$ terpy and Cu-bmpa indicate that these mononuclear $\mathrm{Cu}$ complexes employed with $\mathrm{N}_{3}$-donor ligands are highly selective for the two-electron reduction of $\mathrm{O}_{2}$ to $\mathrm{H}_{2} \mathrm{O}_{2}$. This might open up an alternative pathway for the production of $\mathrm{H}_{2} \mathrm{O}_{2}$. 


\section{ASSOCIATED CONTENT}

\section{(s) Supporting Information}

The Supporting Information is available free of charge at https://pubs.acs.org/doi/10.1021/acs.inorgchem.0c02204.

Experimental methods, stability of Cu-terpy and $\mathbf{C u}$ bmpa in pH 7 buffered electrolyte, EPR spectroscopy, single crystal X-ray crystallography, crystallographic data of Cu-terpy, selected bond distances and angles for $\mathbf{C u}$ terpy, redox behavior of Cu-bmpa in $\mathrm{pH} 7$ phosphate buffer, Randles-Sevcik equation, deposit formation for Cu-terpy and Cu-bmpa, ORR behavior of Cu-bmpa in $\mathrm{pH} 7$ phosphate buffer, difference in lower potential limit for RRDE measurements, RRDE linear sweep voltammetry with $E_{\text {ring }}$ at $0.8 \mathrm{~V}$, formation of $\mathrm{Cu}^{0}$ deposit at low potential, prolonged RRDE chronoamperometry measurements, photometric measurements of $\mathrm{H}_{2} \mathrm{O}_{2}$ production, $\mathrm{H}_{2} \mathrm{O}_{2}$ reduction catalysis by $\mathrm{RDE} L S V$, color change for Cu-bmpa with $\mathrm{H}_{2} \mathrm{O}_{2}$, EQCM experiment of Cu-terpy, catalytic ORR activity at low [catalyst], derivation of eq 4, foot-of-the-wave analysis, and catalytic reaction order (PDF)

\section{Accession Codes}

CCDC 2016453 contains the supplementary crystallographic data for this paper. These data can be obtained free of charge via www.ccdc.cam.ac.uk/data_request/cif, or by emailing data request@ccdc.cam.ac.uk, or by contacting The Cambridge Crystallographic Data Centre, 12 Union Road, Cambridge CB2 1EZ, UK; fax: +44 1223336033.

\section{AUTHOR INFORMATION}

\section{Corresponding Author}

Dennis G. H. Hetterscheid - Leiden Institute of Chemistry, Leiden University, 2300 RA Leiden, The Netherlands;

(1) orcid.org/0000-0001-5640-4416;

Email: d.g.h.hetterscheid@chem.leidenuniv.nl

\section{Authors}

Nicole W. G. Smits - Leiden Institute of Chemistry, Leiden University, 2300 RA Leiden, The Netherlands

Bas van Dijk - Leiden Institute of Chemistry, Leiden University, 2300 RA Leiden, The Netherlands

Iris de Bruin - Leiden Institute of Chemistry, Leiden University, 2300 RA Leiden, The Netherlands

Samantha L. T. Groeneveld - Leiden Institute of Chemistry, Leiden University, 2300 RA Leiden, The Netherlands

Maxime A. Siegler - Department of Chemistry, Johns Hopkins University, Baltimore, Maryland 21218, United States;

() orcid.org/0000-0003-4165-7810

Complete contact information is available at:

https://pubs.acs.org/10.1021/acs.inorgchem.0c02204

\section{Notes}

The authors declare no competing financial interest.

\section{ACKNOWLEDGMENTS}

Financial support was provided by the European Research Council (ERC starting grant 637556 Cu4Energy to D.G.H.H.). N.W.G.S. gratefully acknowledges Dr. Sipeng Zheng for performing the ICP-OES measurements.

\section{REFERENCES}

(1) Gasteiger, H. A.; Kocha, S. S.; Sompalli, B.; Wagner, F. T. Activity benchmarks and requirements for $\mathrm{Pt}$, Pt-alloy, and non-Pt oxygen reduction catalysts for PEMFCs. Appl. Catal., B 2005, 56, 935.

(2) Gröger, O.; Gasteiger, H. A.; Suchsland, J.-P. Reviewelectromobility: Batteries or fuel cells? J. Electrochem. Soc. 2015, 162, A2605-A2622.

(3) Solomon, E. I.; Augustine, A. J.; Yoon, J. $\mathrm{O}_{2}$ reduction to $\mathrm{H}_{2} \mathrm{O}$ by the multicopper oxidases. Dalton Trans. 2008, 3921-3932.

(4) Solomon, E. I.; Sundaram, U. M.; Machonkin, T. E. Multicopper oxidases and oxygenases. Chem. Rev. 1996, 96, 2563-2606.

(5) Farneth, W. E.; D'Amore, M. B. Encapsulated laccase electrodes for fuel cell cathodes. J. Electroanal. Chem. 2005, 581, 197-205.

(6) Hollmann, F.; Gumulya, Y.; Tölle, C.; Liese, A.; Thum, O. Evaluation of the laccase from myceliophthora thermophila as industrial biocatalyst for polymerization reactions. Macromolecules 2008, 41, 8520-8524.

(7) Matijošytè, I.; Arends, I. W. C. E.; Sheldon, R. A.; de Vries, S. Pre-steady state kinetic studies on the microsecond time scale of the laccase from trametes versicolor. Inorg. Chim. Acta 2008, 361, 12021206.

(8) Lalaoui, N.; Elouarzaki, K.; Goff, A. L.; Holzinger, M.; Cosnier, $\mathrm{S}$. Efficient direct oxygen reduction by laccases attached and oriented on pyrene-functionalized polypyrrole/carbon nanotube electrodes. Chem. Commun. 2013, 49, 9281-9283.

(9) Tarasevich, M. R.; Yaropolov, A. I.; Bogdanovskaya, V. A.; Varfolomeev, S. D. Electrocatalysis of a cathodic oxygen reduction by laccase. J. Electroanal. Chem. Interfacial Electrochem. 1979, 104, 393403.

(10) Soukharev, V.; Mano, N.; Heller, A. A four-electron $\mathrm{O}_{2-}$ electroreduction biocatalyst superior to platinum and a biofuel cell operating at 0.88 V. J. Am. Chem. Soc. 2004, 126, 8368-8369.

(11) Mano, N.; Soukharev, V.; Heller, A. A laccase-wiring redox hydrogel for efficient catalysis of $\mathrm{O}_{2}$ electroreduction. J. Phys. Chem. B 2006, 110, 11180-11187.

(12) Blanford, C. F.; Heath, R. S.; Armstrong, F. A. A stable electrode for high-potential, electrocatalytic $\mathrm{O}_{2}$ reduction based on rational attachment of a blue copper oxidase to a graphite surface. Chem. Commun. 2007, 1710-1712.

(13) Cracknell, J. A.; Vincent, K. A.; Armstrong, F. A. Enzymes as working or inspirational electrocatalysts for fuel cells and electrolysis. Chem. Rev. 2008, 108, 2439-2461.

(14) Blanford, C. F.; Foster, C. E.; Heath, R. S.; Armstrong, F. A. Efficient electrocatalytic oxygen reduction by the 'blue' copper oxidase, laccase, directly attached to chemically modified carbons. Faraday Discuss. 2009, 140, 319-335.

(15) Thorum, M. S.; Anderson, C. A.; Hatch, J. J.; Campbell, A. S.; Marshall, N. M.; Zimmerman, S. C.; Lu, Y.; Gewirth, A. A. Direct, electrocatalytic oxygen reduction by laccase on anthracene-2methanethiol-modified gold. J. Phys. Chem. Lett. 2010, 1, 2251-2254.

(16) Davis, F.; Higson, S. P. J. Biofuel cells-recent advances and applications. Biosens. Bioelectron. 2007, 22, 1224-1235.

(17) Vasudevan, P.; Santosh; Mann, N.; Tyagi, S. Transition metal complexes of porphyrins and phthalocyanines as electrocatalysts for dioxygen reduction. Transition Met. Chem. 1990, 15, 81-90.

(18) Zhang, J.; Anson, F. C. Electrochemistry of the $\mathrm{Cu}(\mathrm{II})$ complex of 4,7-diphenyl-1,10-phenanthrolinedisulfonate adsorbed on graphite electrodes and its behavior as an electrocatalyst for the reduction of $\mathrm{O}_{2}$ and $\mathrm{H}_{2} \mathrm{O}_{2}$. J. Electroanal. Chem. 1992, 341, 323-341.

(19) Zhang, J.; Anson, F. C. Complexes of $\mathrm{Cu}$ (II) with electroactive chelating ligands adsorbed on graphite electrodes: Surface coordination chemistry and electrocatalysis. J. Electroanal. Chem. 1993, 348, $81-97$.

(20) Zhang, J.; Anson, F. C. Electrocatalysts for the reduction of $\mathrm{O}_{2}$ and $\mathrm{H}_{2} \mathrm{O}_{2}$ based on complexes of $\mathrm{Cu}$ (II) with the strongly adsorbing 2,9-dimethyl-1,10-phenanthroline ligand. Electrochim. Acta 1993, 38, $2423-2429$. 
(21) Halfen, J. A.; Mahapatra, S.; Wilkinson, E. C.; Kaderli, S.; Young, V. G.; Que, L.; Zuberbühler, A. D.; Tolman, W. B. Reversible cleavage and formation of the dioxygen $\mathrm{O}-\mathrm{O}$ bond within a dicopper complex. Science 1996, 271, 1397.

(22) Lewis, E. A.; Tolman, W. B. Reactivity of dioxygen-copper systems. Chem. Rev. 2004, 104, 1047-1076.

(23) Mirica, L. M.; Ottenwaelder, X.; Stack, T. D. P. Structure and spectroscopy of copper-dioxygen complexes. Chem. Rev. 2004, 104, $1013-1046$.

(24) Cramer, C. J.; Tolman, W. B. Mononuclear $\mathrm{Cu}-\mathrm{O}_{2}$ complexes: Geometries, spectroscopic properties, electronic structures, and reactivity. Acc. Chem. Res. 2007, 40, 601-608.

(25) McCrory, C. C. L.; Ottenwaelder, X.; Stack, T. D. P.; Chidsey, C. E. D. Kinetic and mechanistic studies of the electrocatalytic reduction of $\mathrm{O}_{2}$ to $\mathrm{H}_{2} \mathrm{O}$ with mononuclear $\mathrm{Cu}$ complexes of substituted 1,10-phenanthrolines. J. Phys. Chem. A 2007, 111, 12641-12650.

(26) McCrory, C. C. L.; Devadoss, A.; Ottenwaelder, X.; Lowe, R. D.; Stack, T. D. P.; Chidsey, C. E. D. Electrocatalytic $\mathrm{O}_{2}$ reduction by covalently immobilized mononuclear copper(I) complexes: Evidence for a binuclear $\mathrm{Cu}_{2} \mathrm{O}_{2}$ intermediate. J. Am. Chem. Soc. 2011, 133, 3696-3699.

(27) Kakuda, S.; Peterson, R. L.; Ohkubo, K.; Karlin, K. D.; Fukuzumi, S. Enhanced catalytic four-electron dioxygen $\left(\mathrm{O}_{2}\right)$ and two-electron hydrogen peroxide $\left(\mathrm{H}_{2} \mathrm{O}_{2}\right)$ reduction with a copper(II) complex possessing a pendant ligand pivalamido group. J. Am. Chem. Soc. 2013, 135, 6513-6522.

(28) Thorseth, M. A.; Tornow, C. E.; Tse, E. C. M.; Gewirth, A. A. $\mathrm{Cu}$ complexes that catalyze the oxygen reduction reaction. Coord. Chem. Rev. 2013, 257, 130-139.

(29) Itoh, S. Developing mononuclear copper-active-oxygen complexes relevant to reactive intermediates of biological oxidation reactions. Acc. Chem. Res. 2015, 48, 2066-2074.

(30) Elwell, C. E.; Gagnon, N. L.; Neisen, B. D.; Dhar, D.; Spaeth, A. D.; Yee, G. M.; Tolman, W. B. Copper-oxygen complexes revisited: Structures, spectroscopy, and reactivity. Chem. Rev. 2017, 117, 20592107.

(31) Hong, S.; Lee, Y.-M.; Ray, K.; Nam, W. Dioxygen activation chemistry by synthetic mononuclear nonheme iron, copper and chromium complexes. Coord. Chem. Rev. 2017, 334, 25-42.

(32) Fukuzumi, S.; Lee, Y.-M.; Nam, W. Mechanisms of twoelectron versus four-electron reduction of dioxygen catalyzed by earth-abundant metal complexes. Chem CatChem 2018, 10, 9-28.

(33) Pegis, M. L.; Wise, C. F.; Martin, D. J.; Mayer, J. M. Oxygen reduction by homogeneous molecular catalysts and electrocatalysts. Chem. Rev. 2018, 118, 2340-2391.

(34) Machan, C. W. Advances in the molecular catalysis of dioxygen reduction. ACS Catal. 2020, 10, 2640-2655.

(35) Mangue, J.; Gondre, C.; Pécaut, J.; Duboc, C.; Ménage, S.; Torelli, S. Controlled $\mathrm{O}_{2}$ reduction at a mixed-valent (II,I) $\mathrm{Cu}_{2} \mathrm{~S}$ core. Chem. Commun. 2020, 56, 9636-9639.

(36) Fukuzumi, S.; Kotani, H.; Lucas, H. R.; Doi, K.; Suenobu, T.; Peterson, R. L.; Karlin, K. D. Mononuclear copper complex-catalyzed four-electron reduction of oxygen. J. Am. Chem. Soc. 2010, 132, 6874-6875.

(37) Langerman, M.; Hetterscheid, D. G. H. Fast oxygen reduction catalyzed by a copper(II) tris(2-pyridylmethyl)amine complex through a stepwise mechanism. Angew. Chem., Int. Ed. 2019, 58, 12974-12978.

(38) Karlin, K. D.; Wei, N.; Jung, B.; Kaderli, S.; Niklaus, P.; Zuberbuehler, A. D. Kinetics and thermodynamics of formation of copper-dioxygen adducts: Oxygenation of mononuclear copper(I) complexes containing tripodal tetradentate ligands. J. Am. Chem. Soc. 1993, 115, 9506-9514.

(39) Fry, H. C.; Scaltrito, D. V.; Karlin, K. D.; Meyer, G. J. The rate of $\mathrm{O}_{2}$ and co binding to a copper complex, determined by a "flashand-trap" technique, exceeds that for hemes. J. Am. Chem. Soc. 2003, $125,11866-11871$
(40) Zhang, C. X.; Kaderli, S.; Costas, M.; Kim, E.-i.; Neuhold, Y.M.; Karlin, K. D.; Zuberbühler, A. D. Copper(I)-dioxygen reactivity of $\left[(\mathrm{L}) \mathrm{Cu}^{\mathrm{I}}\right]^{+}(\mathrm{L}=$ tris(2-pyridylmethyl)amine): Kinetic/thermodynamic and spectroscopic studies concerning the formation of $\mathrm{Cu}-\mathrm{O}_{2}$ and $\mathrm{Cu}_{2}-\mathrm{O}_{2}$ adducts as a function of solvent medium and 4-pyridyl ligand substituent variations. Inorg. Chem. 2003, 42, 1807-1824.

(41) Thorseth, M. A.; Letko, C. S.; Rauchfuss, T. B.; Gewirth, A. A. Dioxygen and hydrogen peroxide reduction with hemocyanin model complexes. Inorg. Chem. 2011, 50, 6158-6162.

(42) Das, D.; Lee, Y.-M.; Ohkubo, K.; Nam, W.; Karlin, K. D.; Fukuzumi, S. Temperature-independent catalytic two-electron reduction of dioxygen by ferrocenes with a copper(II) tris[2-(2-pyridyl)ethyl]amine catalyst in the presence of perchloric acid. J. Am. Chem. Soc. 2013, 135, 2825-2834.

(43) Asahi, M.; Yamazaki, S.-i.; Itoh, S.; Ioroi, T. Electrochemical reduction of dioxygen by copper complexes with pyridylalkylamine ligands dissolved in aqueous buffer solution: The relationship between activity and redox potential. Dalton Trans. 2014, 43, 10705-10709.

(44) Asahi, M.; Yamazaki, S.-i.; Itoh, S.; Ioroi, T. Acid-base and redox equilibria of a tris(2-pyridylmethyl)amine copper complex; their effects on electrocatalytic oxygen reduction by the complex. Electrochim. Acta 2016, 211, 193-198.

(45) Marcus, R. A. Electron transfer reactions in chemistry. Theory and experiment. Rev. Mod. Phys. 1993, 65, 599-610.

(46) Castro, I.; Faus, J.; Julve, M.; Philoche-Levisalles, M. Potentiometric study of the formation of hydroxo complexes of $[\mathrm{Cu} \text { (terpy) }]^{2+}$. Synthesis and crystal structure of $\left[\mathrm{Cu}(\right.$ terpy $\left.)\left(\mathrm{H}_{2} \mathrm{O}\right)\right]$ $\left(\mathrm{CF}_{3} \mathrm{SO}_{3}\right)_{2}$. Transition Met. Chem. 1992, 17, 263-269.

(47) Niklas, N.; Hampel, F.; Liehr, G.; Zahl, A.; Alsfasser, R. The reactivity of $\mathrm{n}$-coordinated amides in metallopeptide frameworks: Molecular events in metal-induced pathogenic pathways? Chem. - Eur. J. 2001, 7, 5135-5142.

(48) Butcher, R. J.; Tesema, Y. T.; Yisgedu, T. B.; Gultneh, Y. (acetonitrile)[bis(2-pyridylmethyl)amine]bis(perchlorato)copper(II). Acta Crystallogr., Sect. E: Struct. Rep. Online 2008, 64, m233-m234.

(49) Lazarou, K. N.; Chadjistamatis, I.; Terzis, A.; Perlepes, S. P.; Raptopoulou, C. P. Complexes derived from the copper(II)/ succinamic acid $/ \mathrm{N} \mathrm{N}^{\prime}, \mathrm{N}^{\prime \prime}$-chelate tertiary reaction systems: Synthesis, structural and spectroscopic studies. Polyhedron 2010, 29, 18701879.

(50) Manikandamathavan, V. M.; Rajapandian, V.; Freddy, A. J.; Weyhermüller, T.; Subramanian, V.; Nair, B. U. Effect of coordinated ligands on antiproliferative activity and DNA cleavage property of three mononuclear $\mathrm{Cu}$ (II)-terpyridine complexes. Eur. J. Med. Chem. 2012, 57, 449-458.

(51) Elgrishi, N.; Rountree, K. J.; McCarthy, B. D.; Rountree, E. S.; Eisenhart, T. T.; Dempsey, J. L. A practical beginner's guide to cyclic voltammetry. J. Chem. Educ. 2018, 95, 197-206.

(52) Savéant, J.-M. Molecular catalysis of electrochemical reactions. Mechanistic aspects. Chem. Rev. 2008, 108, 2348-2378.

(53) Martin, D. J.; McCarthy, B. D.; Rountree, E. S.; Dempsey, J. L. Qualitative extension of the $\mathrm{EC}^{\prime}$ zone diagram to a molecular catalyst for a multi-electron, multi-substrate electrochemical reaction. Dalton Trans. 2016, 45, 9970-9976.

(54) Rountree, E. S.; McCarthy, B. D.; Eisenhart, T. T.; Dempsey, J. L. Evaluation of homogeneous electrocatalysts by cyclic voltammetry. Inorg. Chem. 2014, 53, 9983-10002.

(55) El Wakkad, S. E. S.; Emara, S. H. 89. The anodic oxidation of platinum at very low current density. J. Chem. Soc. 1952, 461-466.

(56) Hall, S. B.; Khudaish, E. A.; Hart, A. L. Electrochemical oxidation of hydrogen peroxide at platinum electrodes. Part II: Effect of potential. Electrochim. Acta 1998, 43, 2015-2024.

(57) Zhou, R.; Zheng, Y.; Jaroniec, M.; Qiao, S.-Z. Determination of the electron transfer number for the oxygen reduction reaction: From theory to experiment. ACS Catal. 2016, 6, 4720-4728.

(58) Schumpe, A.; Adler, I.; Deckwer, W.-D. Solubility of oxygen in electrolyte solutions. Biotechnol. Bioeng. 1978, 20, 145-150. 
(59) Tromans, D. Modeling oxygen solubility in water and electrolyte solutions. Ind. Eng. Chem. Res. 2000, 39, 805-812.

(60) Xing, W.; Yin, M.; Lv, Q.; Hu, Y.; Liu, C.; Zhang, J. Oxygen solubility, diffusion coefficient, and solution viscosity. In Rotating electrode methods and oxygen reduction electrocatalysts; Xing, W., Yin, G., Zhang, J., Eds.; Elsevier: Amsterdam, 2014; pp 1-31, DOI: 10.1016/B978-0-444-63278-4.00001-X.

(61) Costentin, C.; Drouet, S.; Robert, M.; Savéant, J.-M. Turnover numbers, turnover frequencies, and overpotential in molecular catalysis of electrochemical reactions. Cyclic voltammetry and preparative-scale electrolysis. J. Am. Chem. Soc. 2012, 134, 1123511242.

(62) Reedijk, J. Metal-ligand exchange kinetics in platinum and ruthenium complexes. Platinum Met. Rev. 2008, 52, 2-11.

(63) Costentin, C.; Savéant, J.-M. Multielectron, multistep molecular catalysis of electrochemical reactions: Benchmarking of homogeneous catalysts. ChemElectroChem 2014, 1, 1226-1236.

(64) Dahl, E. W.; Szymczak, N. K. Hydrogen bonds dictate the coordination geometry of copper: Characterization of a square-planar copper(I) complex. Angew. Chem., Int. Ed. 2016, 55, 3101-3105.

(65) Lim, B. S.; Holm, R. H. Molecular heme-cyanide-copper bridged assemblies: Linkage isomerism, trends in $\nu_{\mathrm{CN}}$ values, and relation to the heme- $\mathrm{a}_{3} / \mathrm{Cu}_{\mathrm{B}}$ site in cyanide-inhibited heme-copper oxidases. Inorg. Chem. 1998, 37, 4898-4908.

(66) Palaniandavar, M.; Butcher, R. J.; Addison, A. W. Dipicolylamine complexes of copper(II): Two different coordination geometries in the same unit cell of $\mathrm{Cu}(\text { Dipica })_{2}\left(\mathrm{BF}_{4}\right)_{2}$. Inorg. Chem. 1996, 35, 467-471. 